\title{
Mapping and Quantifying the Human-Environment Interactions in Middle Egypt Using Machine Learning and Satellite Data Fusion Techniques
}

\author{
José Manuel Delgado Blasco ${ }^{1,2, *}$, , Fabio Cian ${ }^{3,4}\left(\mathbb{D}\right.$, Ramon F. Hanssen $^{1}(\mathbb{D}$ and \\ Gert Verstraeten $^{2}$ (D) \\ 1 Department of Geoscience and Remote Sensing, Delft University of Technology, 2628 CN Delft, \\ The Netherlands; R.F.Hanssen@tudelft.nl \\ 2 Department of Earth and Environmental Sciences, Leuven, Division of Geography and Tourism, \\ KU Leuven-University of Leuven, B-3001 Leuven, Belgium; Gert.Verstraeten@ees.kuleuven.be \\ 3 Department of Economics, Ca' Foscari University Venice, 30121 Venice, Italy; fabio.cian@unive.it \\ 4 The World Bank Group Washington, DC 20433, USA \\ * Correspondence: J.M.DelgadoBlasco@tudelft.nl
}

Received: 14 January 2020; Accepted: 8 February 2020; Published: 10 February 2020

\begin{abstract}
Population growth in rural areas of Egypt is rapidly transforming the landscape. New cities are appearing in desert areas while existing cities and villages within the Nile floodplain are growing and pushing agricultural areas into the desert. To enable control and planning of the urban transformation, these rapid changes need to be mapped with high precision and frequency. Urban detection in rural areas in optical remote sensing is problematic when urban structures are built using the same materials as their surroundings. To overcome this limitation, we propose a multi-temporal classification approach based on satellite data fusion and artificial neural networks. We applied the proposed methodology to data of the Egyptian regions of El-Minya and part of Asyut governorates collected from 1998 until 2015. The produced multi-temporal land cover maps capture the evolution of the area and improve the urban detection of the European Space Agency (ESA) Climate Change Initiative Sentinel-2 Prototype Land Cover 20 m map of Africa and the Global Human Settlements Layer from the Joint Research Center (JRC). The extension of urban and agricultural areas increased over $65 \mathrm{~km}^{2}$ and $200 \mathrm{~km}^{2}$, respectively, during the entire period, with an accelerated increase analysed during the last period (2010-2015). Finally, we identified the trends in urban population density as well as the relationship between farmed and built-up land.
\end{abstract}

Keywords: multi-temporal land cover mapping; machine learning; satellite data fusion; urban growth; land reclamation; landscape dynamics; Egypt; Google Earth Engine; AI4EO

\section{Introduction}

Over the next 25 years, the world's population growth is expected to be concentrated in urban conglomerates within the developing world [1]. The challenges in achieving sustainable urban development will be particularly significant in Africa [2,3]. Over the last decades, urban sprawl resulted in the loss of fertile soil for agricultural food production in the Egyptian Nile Valley. From the time of the 1996 population census onwards, the policy of the Egyptian government has been to avoid new constructions in the Nile floodplain, thus encouraging people to live outside the so-called 'green land' by settling in the arid areas of the eastern and western desert plateau [4]. Despite the restrictions introduced in 1996, inner-city slums have grown and informal settlements have bloomed on the urban fringes [5]. 
Satellite remote sensing can provide rapid information to detect and map new built-up areas, and this information could be accessible by the decision-makers to act accordingly. Many studies have focused on urban sprawl for major centers around the globe [6-8], including Africa [1,9,10]. However, increasing urbanization of the rural areas in the hinterland of major urban centers is less studied [11,12].

Our aim is to analyse the landscape dynamics in Middle Egypt, which is an area of particular importance for several reasons. Compared to larger urban areas, such as Caïro, Middle Egypt is much more rural, yet experiencing a strong demographic trend (population increase) putting large pressure on arable land (see Figure 1). Furthermore, the fertile Nile floodplain is a narrow strip (10-15 km) in an extensive desert area, leaving little space for urban and agricultural development. Next to loss of fertile land, the encroachment of desert areas by anthropogenic activities is, therefore, another major trend in land use.

Additionally, to the west of the Nile floodplain, Middle Egypt is encroached by the South-Rayan dune field that stretches from the south of the Faiyum depression in an NNW-SSE direction $[13,14]$. This dune-field contains barchan dunes migrating at a rate of 2-6 $\mathrm{m}$ per year [14]. Thus, desert dune dynamics at the interface of the floodplain may also lead to sand encroachment into the fertile floodplain [15], and to anchored dunes within large vegetation fields. Moreover, the area is rich in archaeological sites that are threatened by the various land cover changes. Furthermore, the desert margin in Middle Egypt on the western side of the floodplain is also experiencing land reclamation efforts to increase the extent of arable land environments [14].

Whilst many studies have been carried out to analyse Greater Cairo's urban area [16-22], little information is available on changes in land cover and, specifically, the urbanisation of the rural areas in the Nile floodplain upstream (or South) of Cairo. Some regional-scale studies [23] have addressed land cover dynamics in this region, but little or no quantitative spatial information about the evolution of the urban extent of regional cities such as Mallawi is available [24]. The mixture of active or inactive sand dunes, tilled fields on reclaimed desert soils, as well as the construction of buildings in so-called 'mud bricks' makes a detailed analysis of land-use transformations in the Middle Egypt area challenging with optical imagery.

Together with other regions in Africa, Middle Egypt was mapped by the AFRICOVER project [25], using Landsat TM data acquired mainly in 1997. More recently, within the European Space Agency Climate Change Initiative (ESA-CCI), a land cover prototype of Africa has been produced using Sentinel-2 data acquired in 2016 [26]. This approach showed the limitations of optical sensors in distinguishing spectral signatures of urban features made of materials similar to the ones composing the surrounding soil. This holds true for areas where buildings and roads are temporarily covered by sand or dust following intense sand storm events. Similar limitations for the classification of optical images were reported in past land cover classification studies [22].

Previous studies have shown that the fusion of multi-spectral (including optical) remote sensing (MS) data in combination with Synthetic Aperture Radar (SAR) data may overcome this problem and can lead to improved land cover classification $[27,28]$. Given the amount of free multi-spectral and SAR data continuously acquired over the whole globe by different satellite missions, the fusion of the two types of data offers much potential. In this study, such a data fusion approach is followed to quantitatively analyse and map the landscape dynamics in Middle Egypt.

This work aims to create accurate land use land cover maps using the aforementioned data fusion approach to provide precise information about the evolution of urban and agricultural areas in Middle Egypt in relation to changes in population dynamics. 

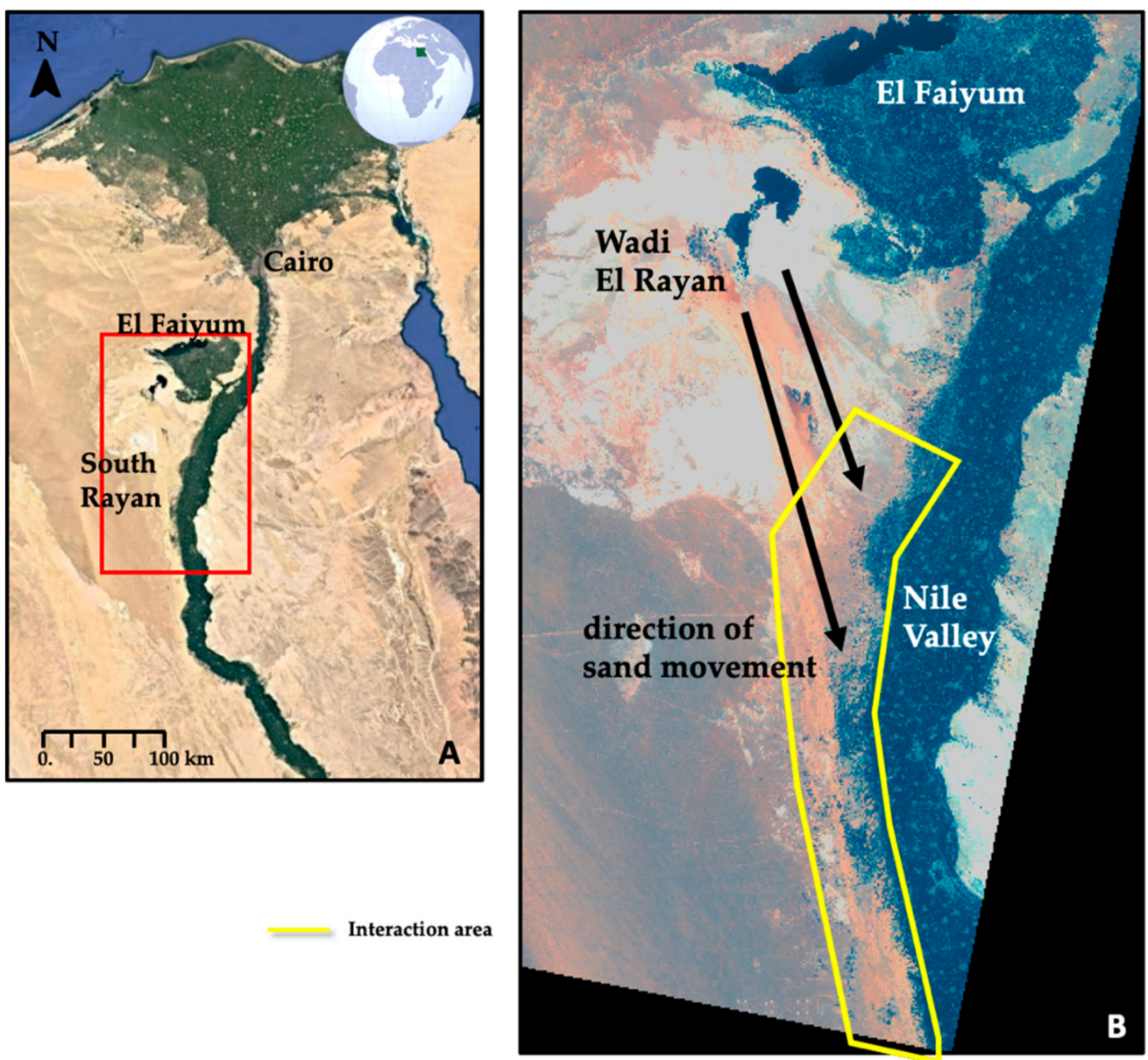

Figure 1. (A) Google Earth image of Egypt indicating the location of (B) within the red rectangle. (B) False-color Landsat 8 OLITIRS image over the South-Rayan dune field and the direction of sand dune movement (source [29]), indicating the interaction area within the yellow polygon.

\section{The Study Area}

The study area is located in Middle Egypt (Figure 2) and includes part of the governorates of El-Minya and Asyut. It stretches from approximately $170 \mathrm{~km}$ to $280 \mathrm{~km}$ south of Caïro and comprises the regional cities of El-Minya, Mallawi and Dayrut from north to south. The study area comprises the Nile floodplain where almost all the urban areas and agricultural land is situated, but also a stretch of desert to the west and east.

Within the Nile floodplain, two major river channels are running south to north, i.e., the Nile River in the eastern part and the Bahr Youssef River in the western part. The latter branches of the Nile River near Dayrut is the main source of water flowing into the Faiyum depression in the North. The total study area comprised of $6170 \mathrm{~km}^{2}$. 

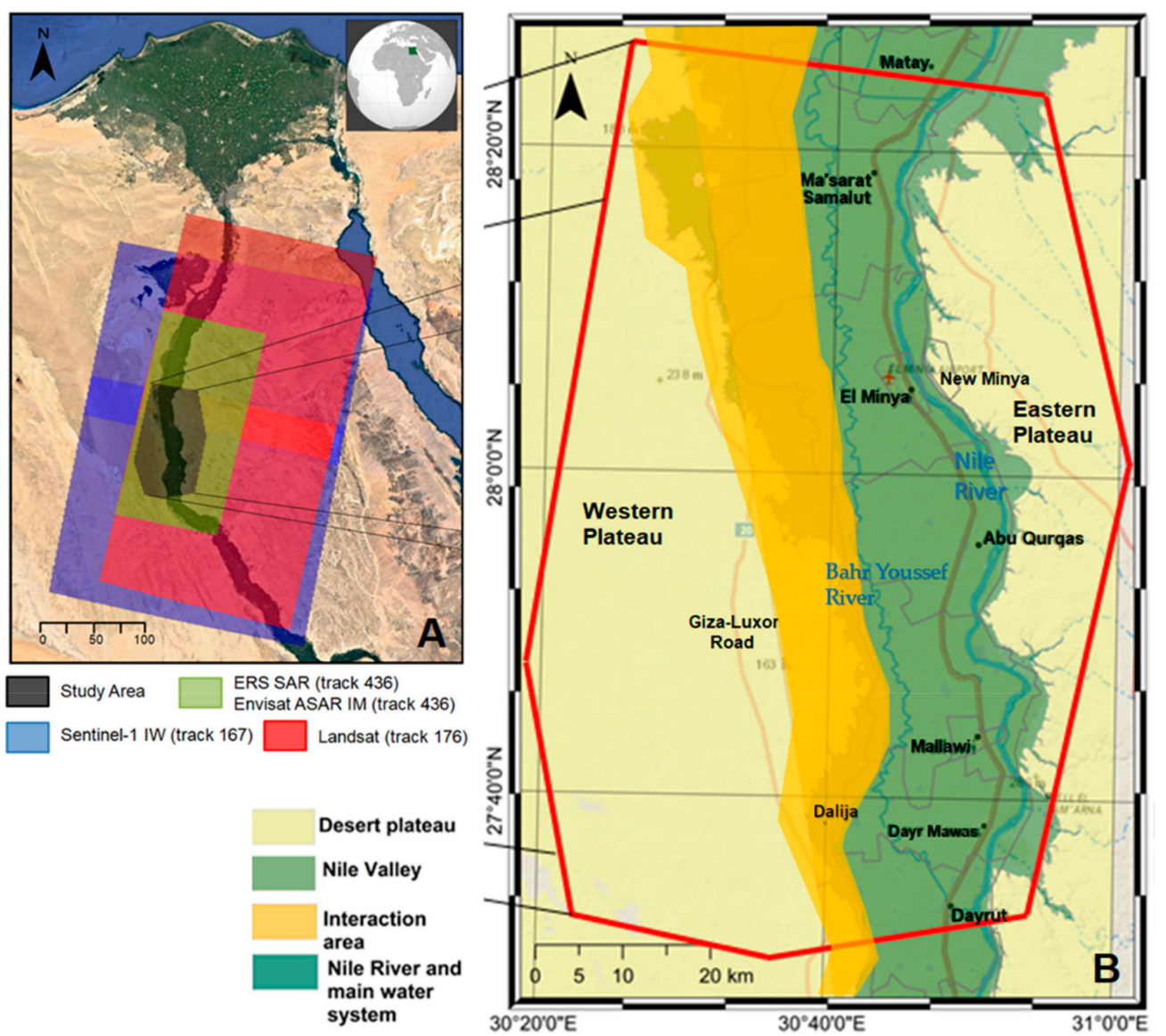

Figure 2. (A) Location of the study area in Middle Egypt (black polygon), over the satellite imagery footprints (background image Google Earth). (B) Detailed map of the study area highlighting the main cities and simplified representation of the landform regions.

\section{Materials and Methods}

In order to overcome the limitations of the optical sensors, we employed a satellite data fusion approach, combining Synthetic Aperture Radar (SAR) and optical multi-spectral data, covering the period from 1998 up to 2015 enabling the analysis of the human-environment interactions for almost three decades. Before 1998, there was not enough data available for the study area to apply this data fusion approach. Information on the selected SAR and optical data are provided in Table 1, whereas the footprint is shown in Figure 2.

Table 1. Characteristics of the selected satellite remote sensing imagery for the resulting land use and land cover (LULC) map.

\begin{tabular}{|c|c|c|c|c|c|}
\hline $\begin{array}{l}\text { LULC Map } \\
\text { Created }\end{array}$ & $\begin{array}{l}\text { Acquisition Dates } \\
\text { Start-Stop }\end{array}$ & Sensor & Signal Characteristics & $\begin{array}{c}\text { Spatial } \\
\text { Resolution }[\mathrm{m}]\end{array}$ & $\begin{array}{c}\mathrm{N} . \\
\text { Images }\end{array}$ \\
\hline \multirow{2}{*}{1998} & 1997-05-15-1999-03-11 & ERS-1/2 SAR & C band, VV channel & $4 \times 20$ & 6 \\
\hline & 1998-01-01-1998-12-31 & Landsat $5 \mathrm{TM}$ & Visible, NIR, SWIR-1/2 & $30 \times 30$ & 32 \\
\hline \multirow{2}{*}{2004} & $2003-11-20-2004-12-09$ & Envisat ASAR & C band, VV channel & $4 \times 20$ & 9 \\
\hline & 2004-01-01-2004-12-31 & $\begin{array}{l}\text { Landsat } 7 \\
\text { EMT+ }\end{array}$ & Visible, NIR, SWIR-1/2 & $30 \times 30$ & 50 \\
\hline \multirow{2}{*}{2010} & 2009-01-22-2010-08-05 & Envisat ASAR & C band, VV channel & $4 \times 20$ & 9 \\
\hline & 2010-01-01-2010-12-31 & $\begin{array}{l}\text { Landsat } 7 \\
\text { ETM+ }\end{array}$ & Visible, NIR, SWIR-1/2 & $30 \times 30$ & 31 \\
\hline \multirow{2}{*}{2015} & 2015-01-01-2015-12-31 & Sentinel-1 IW & C band, VV channel & $20 \times 23$ & 53 \\
\hline & 2015-01-01-2015-12-3 & $\begin{array}{l}\text { Landsat } 8 \\
\text { OLITIRS }\end{array}$ & Visible, NIR, SWIR-1/2 & $30 \times 30$ & 8 \\
\hline
\end{tabular}


To analyse the land cover dynamics in the Middle Egypt region, the methodology employed can be described in the following three steps (Figure 3): (1) data preparation and extraction of land cover indicators; (2) spatio-temporal land use and land cover (LULC) mapping; (3) computation of urban and agricultural land cover changes, and changes in urban population density. Individual steps are further detailed in the following sections.

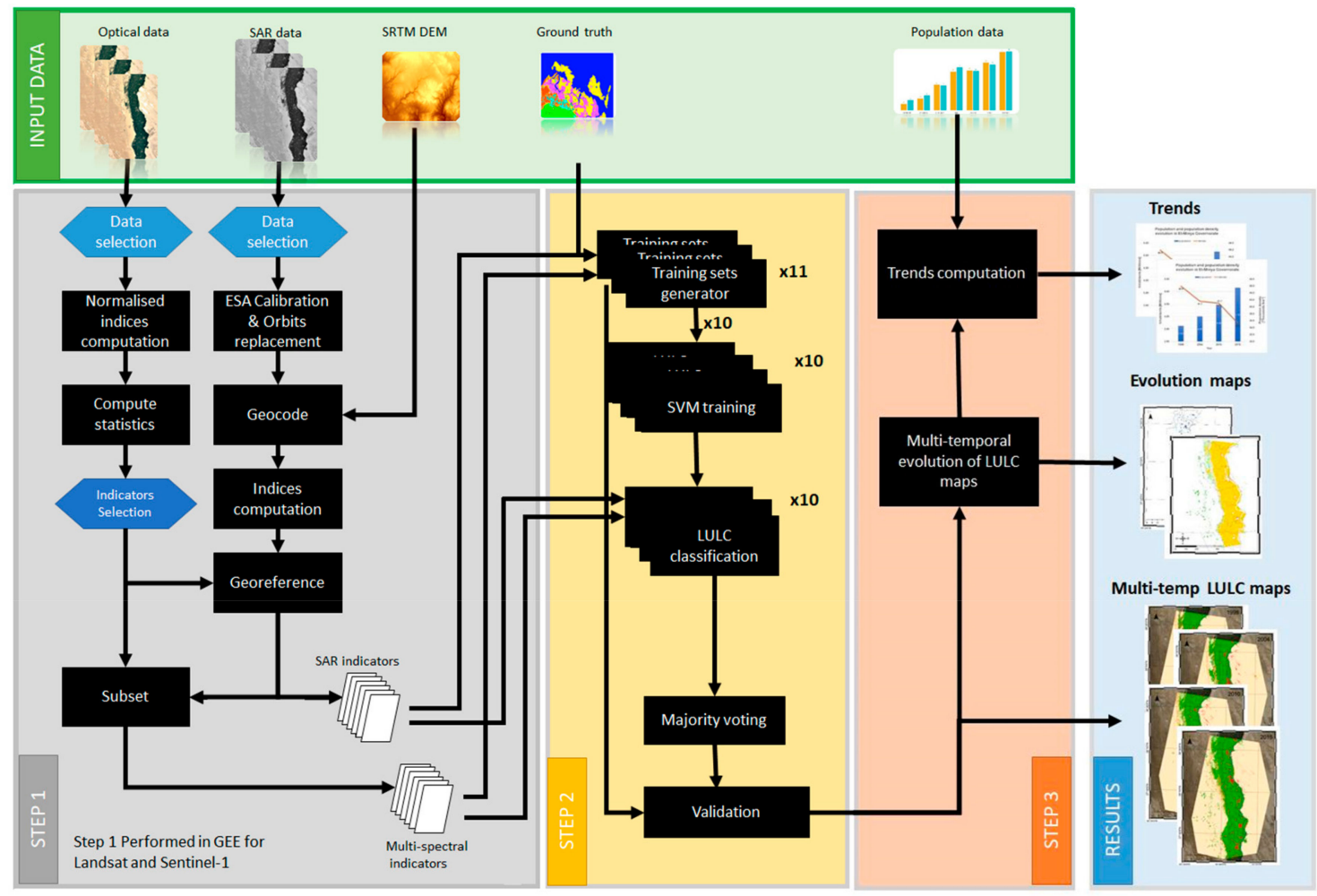

Figure 3. Overview of the methodological approach with the three steps discussed in the text.

\subsection{Step 1: Data Preparation and Indicators Extraction}

Step 1 was implemented within Google Earth Engine (GEE) [30] for the analysis of the Landsat (5 TM, 7 ETM+, and 8 OLITIRS) and Sentinel-1 IW GRD imagery, as it allows direct access and processing of the datasets to export the indicators used as input in step 2.

However, as the historical ERS SAR and Envisat ASAR are not available within GEE, these images were processed on a Virtual Machine provided by the ESA Research and Service Support through their CloudToolbox service [31]. These ERS and Envisat SAR datasets were calibrated using the ESA specifications in NEST [32] and calibrated SAR images were geocoded using the Digital Elevation Model from the Shuttle Radar Topography Mission. The resulting datasets were grouped in three periods: (i) ERS dataset acquired in a time range centered around 1998; (ii) Envisat data acquired around 2004; and (iii) Envisat data acquired in 2010 (see Table 1).

Finally, the images were registered with the corresponding Landsat dataset, using 20 ground control points that were manually selected and uniformly distributed over the study area and represent road intersections on the satellite images. The georeferenced SAR images were resampled using a linear polynomial, obtaining a final Root Mean Square Error (RMSE) lower than 1 pixel (30 m) for all the different cases. Optical images were finally cropped to match the SAR data extent. At the end of the data preparation, all data were unified to the same image resolution, namely $30 \mathrm{~m}$ posting, and georeferenced in the Universal Transverse Mercator (UTM) projection (Zone 36N) and World Geodetic System 84 (WGS84) Datum. 
Satellite-Derived Indicators for Land-Cover Classification

Different sets of indicators, feeding the land-cover supervised classifier, are defined for SAR and multi-spectral data. Regarding the SAR data, we selected indicators (see Table 2) with significant temporal statistical information per pixel [18]. Different land cover classes are expected to exhibit different statistical backscatter properties. Among those, urban areas have the lowest temporal standard deviation as opposed to crop fields or water, which exhibit larger fluctuation of the signal measured over time.

Regarding the multi-spectral data, instead of using single spectral bands, often a linear combination of bands is used on normalised differences of different bands [28,33,34]. Traditionally, many indexes (e.g., NDVI) have been defined as the normalised difference of two bands with the aim of highlighting specific features of the land, such as vegetation, water surfaces and built-up areas [34-37]. The advantages of this method are manifold. Firstly, data are globally consistent. Secondly, the information provided by each index gives the opportunity of analysing the contribution of different features in mixed urban areas. Finally, the risk of ambiguities is minimised since the different indexes complement each other in distinguishing the land cover classes. This approach has been found to be effective by several studies [34,38-40] and has been selected as the starting point of this work.

As shown in Table 2, for SAR data, the following indicators were investigated: (i) temporal average calibrated SAR backscatter expressed in decibel scale (dB); (ii) temporal standard deviation of calibrated SAR backscatter signal per pixel in dB; (iii) temporal coefficient of variation of calibrated SAR signal per pixel in $\mathrm{dB}$ and; (iv) coefficient of dispersion in linear scale.

Table 2. Formulas of the four selected indicators of SAR derived information employed as input in the land use/land cover (LULC) classifier. Each index is calculated within the temporal data series of each pixel $\mathrm{i}$ and $\mathrm{K}$ images, with $\mathrm{K} \in[1, \mathrm{~N}]$, being $\mathrm{N}$ the total number of images.

\begin{tabular}{cc}
\hline Indicators & Formula \\
\hline Backscatter average $[\mathrm{dB}]$ & $\mu_{a_{i}}=10 \log _{10} \frac{1}{N} \sum_{\{k=1\}}^{N} a_{k, i}$ \\
\hline Backscatter standard deviation $[\mathrm{dB}]$ & $\sigma_{a_{i}}=10 \log _{10} \sqrt{\frac{1}{N-1} \sum_{\{k=1\}}^{N}\left(a_{k, i}-10^{\frac{\mu a_{i}}{10}}\right)^{2}}$ \\
\hline Coefficient of variation $[\mathrm{dB}]$ & $\sigma_{n o r m_{i}}=10 \log _{10}\left(\frac{10 \frac{\sigma a_{i}}{10}}{1 \mu_{a_{i}}}\right)$ \\
\hline Coefficient of dispersion & $D_{i}=\frac{10 \frac{\mu a_{i}}{10}}{10 \frac{\sigma a_{i}}{10}}$ \\
\hline
\end{tabular}

As shown in Table 3, for multi-spectral data the following normalised ratios were computed: (i) Normalised Difference Built-up Index (NDBI); (ii) Normalised Difference Water Index (NDWI); (iii) Normalised Difference Vegetation Index (NDVI) and; (iv) Normalised Difference between SWIR-1 and SWIR-2. Of these indicators, the 95th percentiles, respectively, were computed from the temporal distribution ( $N$ images) of each pixel $(i)$ and selected as the final indicators. Using this 95th percentile, we avoid artefacts in the data such as the ones produced by the cloud covered data. 
Table 3. Formulas of the four normalised ratios derived from each of the multi-spectral datasets. Each index is calculated within the temporal data series of each pixel $i$ and $K$ images, with $K \in[1, N]$, being $\mathrm{N}$ the total number of images.

\begin{tabular}{cc}
\hline \multicolumn{1}{c}{ Indicators } & Formula \\
\hline Normalised Difference Built-up Index & $\mathrm{NDBI}_{k, i}=\frac{\mathrm{SWIR}_{k, i}-\mathrm{NIR}_{k, i}}{\mathrm{SWIR}_{k, i}+\mathrm{NIR}_{k, i}}$ \\
\hline Normalised Difference Water Index & $\mathrm{NDWI}_{k, i}=\frac{\mathrm{GREEN}_{k, i}-\mathrm{SWIR}_{k, i}}{\mathrm{GREEN}_{k, i}+\mathrm{SWIR}_{k, i}}$ \\
\hline Normalised Difference Vegetation Index & $\mathrm{NDVI}_{k, i}=\frac{\mathrm{NIR}_{k, i}-\mathrm{RED}_{k, i}}{\mathrm{NIR}_{k, i}+\mathrm{RED}_{k, i}}$ \\
\hline Normalised Difference SWIR channels & $\mathrm{NDSWIR12}_{k, i}=\frac{\operatorname{SWIR}_{k, i}-\mathrm{SWIR}_{k, i}}{\operatorname{SWIR}_{k, i}+\mathrm{SWIR}_{k, i}}$ \\
\hline
\end{tabular}

\subsection{Step 2: Land Cover Mapping}

In this work, we have chosen a pixel-based feature fusion approach, using the aforementioned pixel-based indicators as an input of the supervised classifier.

\subsubsection{Supervised Classifiers}

We made use of an open-source $\mathrm{C}++$ suite of utilities for remote sensing (RS) image processing [41]. This suite implements support vector machine (SVM) models that are machine learning supervised learning models with associated algorithms. In particular, the suite implements a supervised classification SVM model (C-SVM) based on the library libSVM and it uses a radial basis function (RBF) kernel [42,43]. Several steps are needed in order to perform a classification: (i) the input indicators composing the dataset to be classified were scaled in order to avoid values spanning greater numeric ranges dominate those with smaller numeric ranges (e.g., normalised between -1 and 1); (ii) a training dataset (a shapefile of points) was prepared for each target class using Google Earth where each point corresponds to an array containing the correspondent values of the input indicators for that pixel; (iii) using the RBF kernel, the optimal parameters $\mathrm{C}$ (penalty parameter for the wrong classification) and $g$ (transformation parameter in the kernel) were obtained maximising the accuracy in classifying test data. These $\mathrm{C}$ and $\mathrm{g}$ parameters were obtained using the pkopt function provided within the pktools package, which iteratively explores in the user-defined range of $C$ and $g$ values until finding the local minimum that minimises the errors produced by the classifier. At this stage, the classification engine was ready to process and classify unseen data.

\subsubsection{Land Cover Classes}

We have defined five classes to be employed to create our classification maps. Four generic classes: (i) built-up area, hereafter named 'urban'; (ii) sandy and rocky desert combined into a 'desert' class; (iii) vegetation, crops, garden, grass, and agricultural fields named as 'field' and; (iv) 'water' class mainly formed by the Nile River and smaller water bodies present in the scene. Finally, our fifth class named 'dunes' identifiable thanks to the data fusion approach, not only inside the desert but also inside the floodplain. This class is expected to be characterised by having high temporal variability of the radar signal, with high optical radiance values characteristic of a sandy desert. 'Dunes' and 'desert' behave differently from the SAR response of each of them.

\subsubsection{Land Cover Classification}

Land cover classification was performed by labelling land cover maps using the aforementioned five classes. We investigated the temporal continuity of land classes in subsequent LULC maps, with special focus on the transitions: (i) 'urban' $\rightarrow$ 'field'; (ii) 'field' $\rightarrow$ 'desert'; and (iii) 'dunes' $\rightarrow$ 'crop'. 
The training dataset retrieved from the labelled classes using Google Earth, which was split into 11 sets, of which 10 were used to train as many classifiers, and 1 used as ground truth dataset for final validation. Subsequently, each classifier was applied to the datasets referring to the various years studied, thus returning 10 intermediate classifications per dataset. Unique final classification maps were obtained by feeding the intermediate results to a majority voting condition. The majority voting strategy assigns a pixel to class ' $X$ ' if it was classified as ' $X$ ' in 6 or more classification maps obtained for the same period.

\subsubsection{Validation Approaches}

The proposed method is validated by evaluating the goodness of the resulting individual classification maps against the ground truth datasets by calculating the standard metrics typically employed in classification purposes, such as overall accuracy and Cohen's Kappa index [44], as detailed in Section 3.2.4.1, as well as qualitatively comparing our resulting LULC maps with state-of-the-art available datasets, as detailed in Section 3.2.4.2.

\subsubsection{Validation against Ground Truth Datasets}

The ground truth datasets were selected from the high-resolution $(<3 \mathrm{~m})$ historical imagery copyrighted by DigitalGlobe and available in Google Earth as of 2016. Different point sets were selected for the time periods 2004, 2010, and 2015. No data referring to 1998 was available when this work was performed. We computed the accuracy of the final classification maps using the overall accuracy and Cohen's Kappa (K) index, as performed by Congalton [45] and Mather [46], in order to keep into account agreement occurring by chance.

\subsubsection{Comparison with State-of-the-Art Datasets}

We employed independent state-of-the-art datasets to compare our results, namely: (i) the Global Urban Footprint (GUF) [47,48], processed by the German Aerospace Centre (DLR); (ii) the Prototype of Sentinel-2 Land Cover Map of Africa at $20 \mathrm{~m}$ [49] released by the European Space Agency Climate Change Initiative (ESA-CCI); (iii) Global Human Settlements Layer using Landsat data for 2014 [50] (GHSL-L8), created by the Joint Research Center (JRC) and; (iv) Global Human Settlements Layer using Sentinel-1 data for 2016 [51] (GHSL-S1) with a $19 \mathrm{~m}$ spatial resolution [52], also created by the JRC. Note that the GUF, ESA-CCI and GSHL-S1 have a higher resolution than our results (30 m) and none of them totally matches the observation time of the data analysed here.

Due to the heterogeneity of the different datasets (data sensor employed, spatial resolution, dates), in order to compare these, a harmonisation process is needed. All datasets were resampled with $30 \mathrm{~m}$ resolution and re-projected in the same projection system of our dataset.

Finally, we compared the urban class across the different datasets: GUF, GHSL-S1 and GHSL-L8, ESA-CCI and our classification maps for 2010 and 2015.

\subsection{Step 3: Multi-Temporal Evolution Analysis}

After obtaining the five-class LULC maps for the four time periods, we identified pixels that remained stable and those that underwent changes from one land-use class to another between 1998 and 2015. Non-realistic changes were also detected and labelled as miss-classified pixels, based on our "multi-temporal consistency rules", defined as follows: (1) once a pixel is urban, it will stay urban in the following periods; (2) water cannot turn into urban, field or desert; (3) fields can only become urban, and not desert or water. In our study area the water class mainly corresponds to the Nile River, and was stable during the considered time period and; (4) desert can change to urban land or crop fields, as well as to dunes. In the latter case, it implies that dunes have been migrating into rocky deserts or across desert pavement surfaces.

In the Middle Egypt region, rule 2 is a simplification as there has effectively been a change in the size of the islands in the Nile channel which may have impacted the area classified as water or 
agriculture. However, as this does not have an impact on the urbanised areas, being the focus of this work, we believe that this simplification is justified.

With the temporal evolution maps for the urban and field classes, together with the population data from Central Agency for Public Mobilization and Statistics of Egypt (CAPMAS) [53], we have computed the trends of urban population density and field area per person. Since these data were not available for the entire study area, this analysis was limited to El-Minya governorate which is centrally located in the study area, as shown in Figure 4.

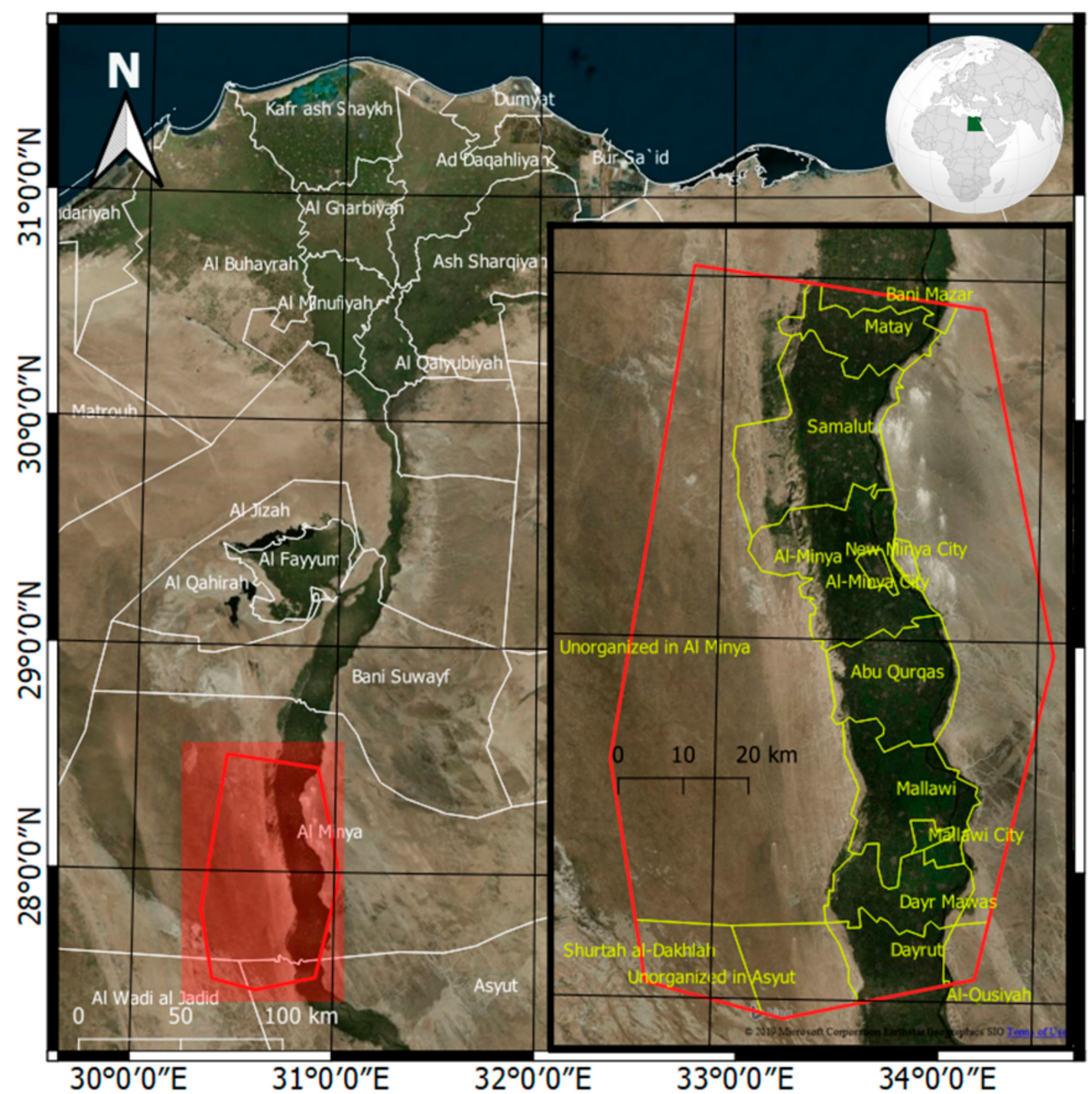

Figure 4. Google Earth image overlaid with the Egyptian administrative boundaries of its governorates (left), and zoom over the location of our study area with the district boundaries (right).

\section{Results}

Figure 5 shows the resulting land use and land cover maps for 1998, 2004, 2010 and 2015. Areas with important changes in LULC between 1998 and 2015 are indicated in Figure 5 as well. These areas include new urbanisation (black rectangles) both in the Eastern Deserts and within the Nile floodplain, expansion of irrigated agriculture in the Western Desert (cyan rectangles) and reclamation of dune fields in the interaction area with the expansion of agriculture (red rectangles). 

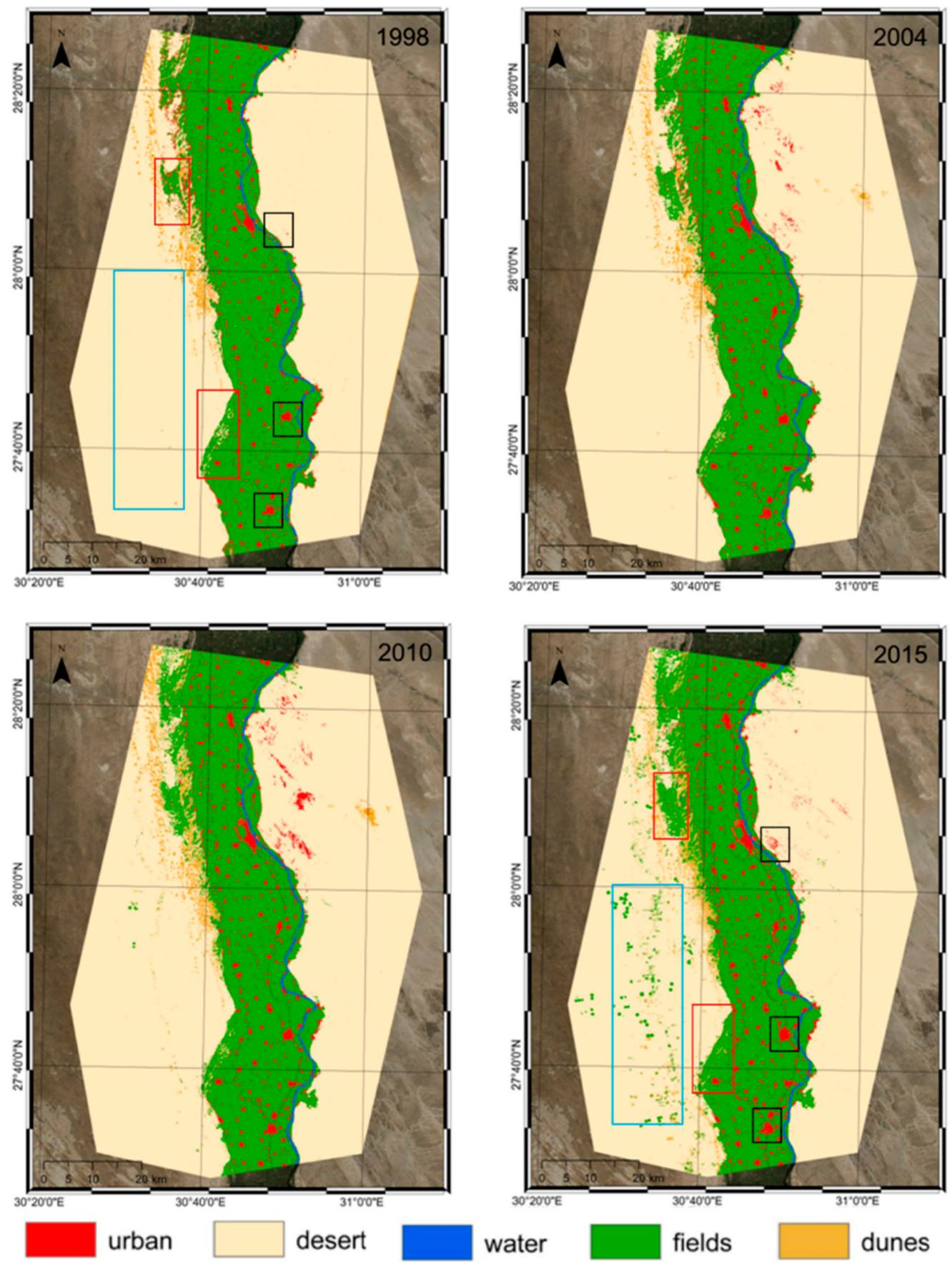

Figure 5. LULC maps obtained over the study area with a data fusion approach using SAR and multi-spectral data for 1998 and 2015. Black rectangles highlight areas with an urban increase, cyan rectangles correspond with fields increase in the desert area and red rectangles with crop increase within the Nile Valley and interaction area.

The accuracy of the land use and land cover maps is expressed in the confusion matrix, see Table 4. Overall, the agreement between the constructed LULC maps and ground truth data is very high as is illustrated by a Kappa index above 0.98 for the different time periods, which is considered an almost perfect agreement [54]. Note that for the period of 1998, historical data in Google Earth over our study area was not available. 
Table 4. Confusion matrix, Kappa index and overall accuracy of the resulting land use maps. Google Earth data are used as ground truth.

\begin{tabular}{|c|c|c|c|c|c|c|c|}
\hline \multirow{2}{*}{ Year } & \multirow{2}{*}{$\begin{array}{c}\text { Ground } \\
\text { Truth }\end{array}$} & \multicolumn{5}{|c|}{ Land Use Classification Map } & \multirow{2}{*}{$\begin{array}{c}\text { Accuracy } \\
\text { Criteria }\end{array}$} \\
\hline & & Urban & Desert & Water & Fields & Dunes & \\
\hline \multirow{5}{*}{2004} & Urban & 431 & 1 & 0 & 0 & 0 & \multirow{5}{*}{$\begin{array}{c}\text { Kappa Index } \\
99.0 \% \\
\text { Overall accuracy } \\
99.5 \%\end{array}$} \\
\hline & Desert & 1 & 6081 & 0 & 0 & 22 & \\
\hline & Water & 0 & 0 & 150 & 0 & 0 & \\
\hline & Fields & 0 & 0 & 0 & 1936 & 0 & \\
\hline & Dunes & 0 & 17 & 0 & 0 & 186 & \\
\hline \multirow{5}{*}{2010} & Urban & 431 & 0 & 0 & 0 & 0 & \multirow{5}{*}{$\begin{array}{c}\text { Kappa Index } \\
99.1 \% \\
\text { Overall accuracy } \\
99.6 \%\end{array}$} \\
\hline & Desert & 1 & 6088 & 1 & 0 & 21 & \\
\hline & Water & 0 & 0 & 151 & 0 & 0 & \\
\hline & Fields & 0 & 0 & 0 & 1936 & 0 & \\
\hline & Dunes & 0 & 13 & 0 & 0 & 189 & \\
\hline \multirow{5}{*}{2015} & Urban & 430 & 0 & 0 & 0 & 0 & \multirow{5}{*}{$\begin{array}{c}\text { Kappa Index } \\
99.1 \% \\
\text { Overall accuracy } \\
99.6 \%\end{array}$} \\
\hline & Desert & 1 & 6092 & 1 & 0 & 13 & \\
\hline & Water & 0 & 0 & 147 & 0 & 0 & \\
\hline & Fields & 1 & 2 & 5 & 1936 & 7 & \\
\hline & Dunes & 0 & 7 & 0 & 0 & 193 & \\
\hline
\end{tabular}

Table 5 clearly shows an increase in built-up areas in both the Nile Valley and the desert however, in the latter region, urbanization mainly took place between 2010 and 2015. Similarly, "land reclamation", i.e., the extension of agricultural fields in former desert environments, became more significant in the final period (2015), i.e., an 11-fold increase in its extent in comparison with the first period (2004), reaching a total new field class of almost $260 \mathrm{~km}^{2}$ for the period between 2010 and 2015. Another visible trend is the constant reduction of the field class within the Nile Valley, as a consequence of the continuous urbanisation over the fertile soil of the Nile Valley. From 1998 to 2015, almost $54 \mathrm{~km}^{2}$ of arable land has been transformed into urbanized land cover in the Nile floodplain.

Table 5. Evolution in urban and field classes across the different landforms from 1998 to $2015\left(\mathrm{~km}^{2}\right)$.

\begin{tabular}{cccccc}
\hline \multirow{2}{*}{ Class } & \multirow{2}{*}{ Landform } & \multicolumn{4}{c}{ Year } \\
\cline { 3 - 6 } & & $\mathbf{1 9 9 8}$ & $\mathbf{2 0 0 4}$ & $\mathbf{2 0 1 0}$ & $\mathbf{2 0 1 5}$ \\
\hline \multirow{2}{*}{ Field } & Valley & 1705.1 & 1690.13 & 1679.73 & 1651.99 \\
& Desert & 0 & 22.06 & 46.52 & 259.69 \\
\hline \multirow{2}{*}{ Urban } & Valley & 85.49 & 100.46 & 110.86 & 138.61 \\
& Desert & 0 & 2.33 & 4.74 & 13.81 \\
\hline
\end{tabular}

The temporal evolution of the different land use classes is extremely interlinked (field $\rightarrow$ urban, field $\rightarrow$ desert/dune, desert $\rightarrow$ dune, desert $\rightarrow$ field, desert $\rightarrow$ urban, dune $\rightarrow$ field, dune $\rightarrow$ urban), since an increase in one class is directly translated into the reduction of others. This is the case, for example, for the urban increase on the first periods analysed (1998-2010), when most of the newly built-up area was located on the edges of the cities and villages (see Figure 6), and the increase in fields was due to the "land reclamation" phenomena mainly linked to the reduction of desert classes by introducing crop fields with irrigation systems inside the arid environment (see Figure 7). 

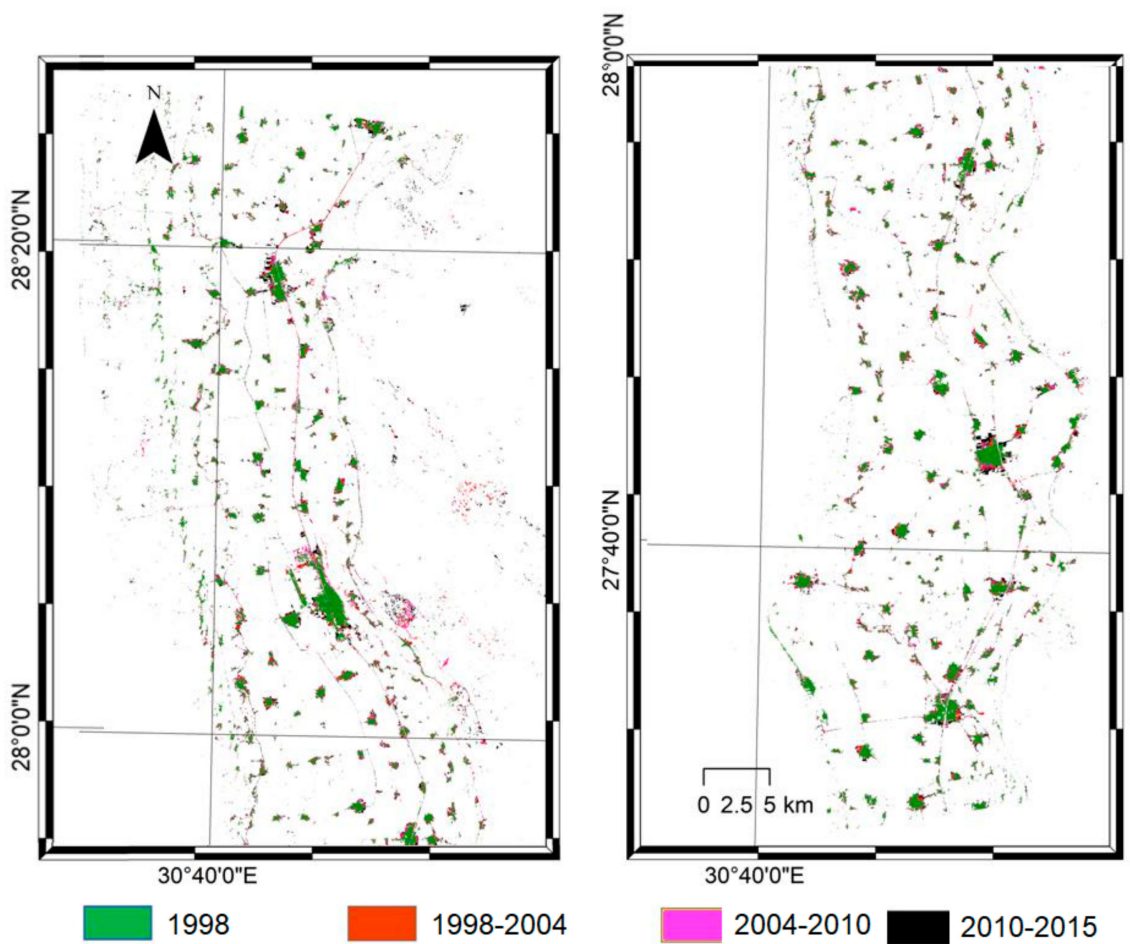

Figure 6. Urban expansion in the study area from 1998 to 2015. Green areas were already urban in 1998 whereas other colours show where urban expansion occurred during the corresponding time period.

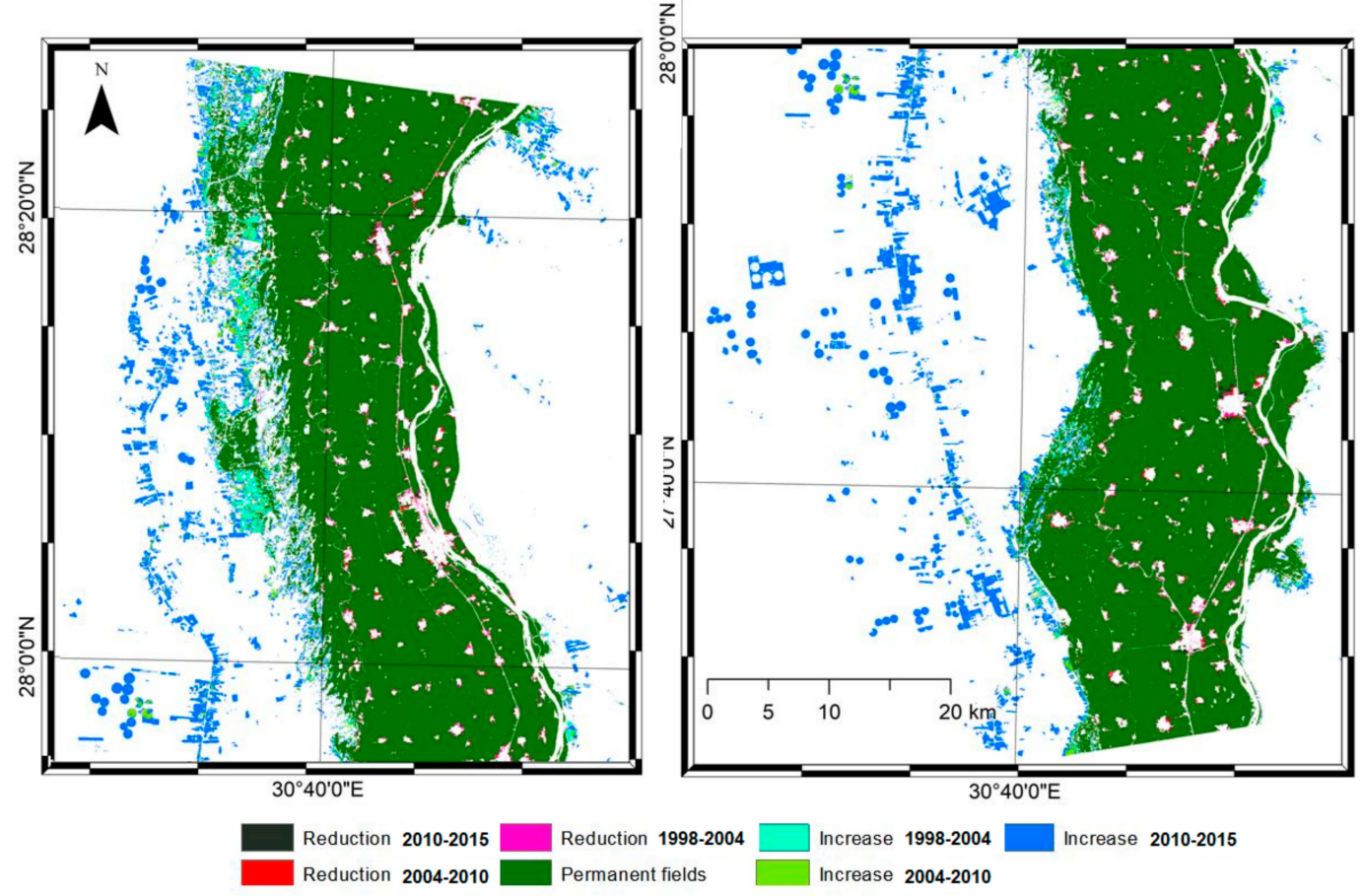

Figure 7. Changes in the spatial extent of agricultural fields for the El-Minya governorate from 1998 to 2015. Permanent fields in the edges indicate the limits of the Nile valley floodplain.

The urban extent and its evolution per district in the El-Minya governorate are summarised in Table 6. Growth rates vary between 0.01 and $0.61 \mathrm{~km}^{2} / \mathrm{yr}$. Over the entire period, urban areas have increased from 33 to $888 \%$ by 2015 compared to 1998 . The lowest percentage increase is for El-Minya 
city itself, whereas a more prominent increase is observed for the new cities in the desert (New Minya and unorganized El-Minya district).

Table 6. Urban spatial extent $\left(\mathrm{km}^{2}\right)$ within the different analysed districts in Middle Egypt for four time periods, and urban growth rates (\% and $\mathrm{km}^{2} / \mathrm{yr}$ ) for the period 1998-2015 (total size of the study area equals $6170 \mathrm{~km}^{2}$ ).

\begin{tabular}{|c|c|c|c|c|c|c|c|}
\hline \multirow[t]{2}{*}{ District } & \multirow{2}{*}{$\begin{array}{l}\text { District Area * } \\
\left(\mathrm{km}^{2}\right)\end{array}$} & \multicolumn{4}{|c|}{ Urban Spatial Extent $\left(\mathrm{km}^{2}\right)$} & \multicolumn{2}{|c|}{$\begin{array}{c}\text { Urban Growth Rate } \\
\text { 1998-2015 }\end{array}$} \\
\hline & & 1998 & 2004 & 2010 & 2015 & $\%$ & $\mathrm{~km}^{2} / \mathrm{yr}$ \\
\hline Abu Qurqas & 279.42 & 10.54 & 13.33 & 14.81 & 19.07 & 80.93 & 0.47 \\
\hline El-Minya & 356.24 & 10.97 & 13.86 & 15.94 & 21.29 & 94.07 & 0.57 \\
\hline El-Minya City & 21.80 & 6.62 & 7.49 & 8.06 & 8.86 & 33.84 & 0.12 \\
\hline Dayr Mawas & 195.85 & 7.32 & 8.96 & 10.06 & 12.81 & 75.00 & 0.31 \\
\hline Dayrut & 221.66 & 11.9 & 13.68 & 14.99 & 18.61 & 56.39 & 0.37 \\
\hline Mallawi & 294.51 & 10.66 & 13.08 & 14.66 & 18.39 & 72.51 & 0.43 \\
\hline Mallawi City & 17.96 & 3.13 & 3.58 & 3.91 & 5.13 & 63.90 & 0.11 \\
\hline Matay & 169.03 & 3.18 & 3.63 & 4.08 & 5.67 & 78.30 & 0.14 \\
\hline New Minya City & 15.66 & 0.08 & 0.15 & 0.23 & 0.79 & 887.50 & 0.04 \\
\hline Samalut & 468.49 & 12.29 & 15.19 & 17.24 & 23.34 & 89.91 & 0.61 \\
\hline Surtah Al Dakhlah & 177.72 & 0.09 & 0.09 & 0.1 & 0.24 & 166.67 & 0.01 \\
\hline Unorganised Asyut & 254.18 & 0.09 & 0.09 & 0.11 & 0.24 & 169.00 & 0.01 \\
\hline $\begin{array}{c}\text { Unorganised } \\
\text { El-Minya }\end{array}$ & 3697.48 & 2.07 & 3.06 & 4.83 & 11.51 & 456.04 & 0.52 \\
\hline Total & 6170 & 78.85 & 96.09 & 108.9 & 145.74 & 84.83 & 3.72 \\
\hline
\end{tabular}

Figure 8 shows the evolution in population density for the built-up environment in El-Minya governorate. These values were calculated by dividing the population census data by the urban spatial extent as shown in Table 6. Overall, there is a decrease from 46 thousand people $/ \mathrm{km}^{2}$ urban area in 1998 to 35 thousand people $/ \mathrm{km}^{2}$ urban area in 2015. Figure 8. also shows how with an increasing population but a decrease in the class 'fields', the average size of agricultural land available per inhabitant is decreasing from 4.7 ha/person in 1998 to 3.6 in 2015.

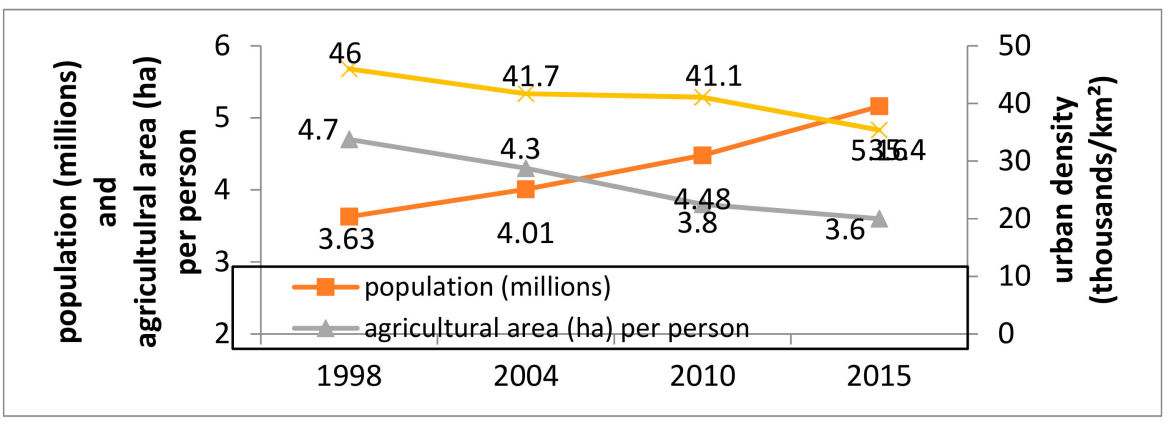

Figure 8. Changes in population, urban population density and agricultural land per person in El-Minya governorate in the period 1998-2015.

Finally, we compared the urban features detected using our approach with the state-of-the-art urban global datasets, such as GUF and GHSL, as well as the urban class from the ESA-CCI Land Cover Prototype over Africa. Additionally, we computed the urban extent detected on El-Minya governorate, in order to understand whether it is possible or not to use these datasets together for urban expansion analysis. Details of the urban extent measured per dataset are shown in Table 7. 
Table 7. Characteristics of the different urban layers and land cover maps employed and measured urban extent across the El-Minya governorate. The temporal evolution of the urban extent shows unrealistic urban extension over time, as urban extent only increased in our study area during that period.

\begin{tabular}{cccccc}
\hline Year & $\begin{array}{c}\text { Urban Extent } \\
{\left[\mathbf{k m}^{\mathbf{2}]}\right.}\end{array}$ & Producer & Data Employed & $\begin{array}{c}\text { Dataset } \\
\text { Name }\end{array}$ & $\begin{array}{c}\text { Spatial } \\
\text { Resolution } \\
{[\mathbf{m}]}\end{array}$ \\
\hline 2010 & $\mathbf{1 0 9 . 0}$ & Our & Envisat ASAR IMS/Landsat 7 & Results & 30 \\
2012 & $\mathbf{1 8 4 . 3 5}$ & DLR & TerraSAR-X/TanDEM-X & GUF & 12 \\
2014 & $\mathbf{2 0 7 . 3 1}$ & JRC & Landsat 8 OLITIRS & GHSL-L8 & 38 \\
2015 & $\mathbf{1 4 8 . 8 8}$ & Our & Sentinel-1/Landsat 8 OLITIRS & Results & 30 \\
2016 & $\mathbf{1 4 5 . 8 1}$ & ESA & Sentinel-2 & ESA-CCI & 20 \\
2016 & $\mathbf{1 4 7 . 4 5}$ & JRC & Sentinel-1 & GHSL-S1 & 19 \\
\hline
\end{tabular}

Additionally, we put together all the datasets shown in Table 7 . to visually compare the urban extent over two smaller areas contained within our study area, one over El-Minya City and surroundings (Figure 9) and the second one over Mallawi and surroundings (Figure 10), from where it was possible to obtain additional information regarding old urban extent and modern cemeteries from Willems et al. [55]. The main differences are highlighted within colour ellipses in these figures and described in the discussion section. It is important to note the nonrealistic changes in the temporal evolution of detected urban extent for different datasets as seen in Table 7. and Figure 9. These inconsistencies reveal the limitations of performing a blind analysis using data obtained from different producers with their particular data sources and methods.
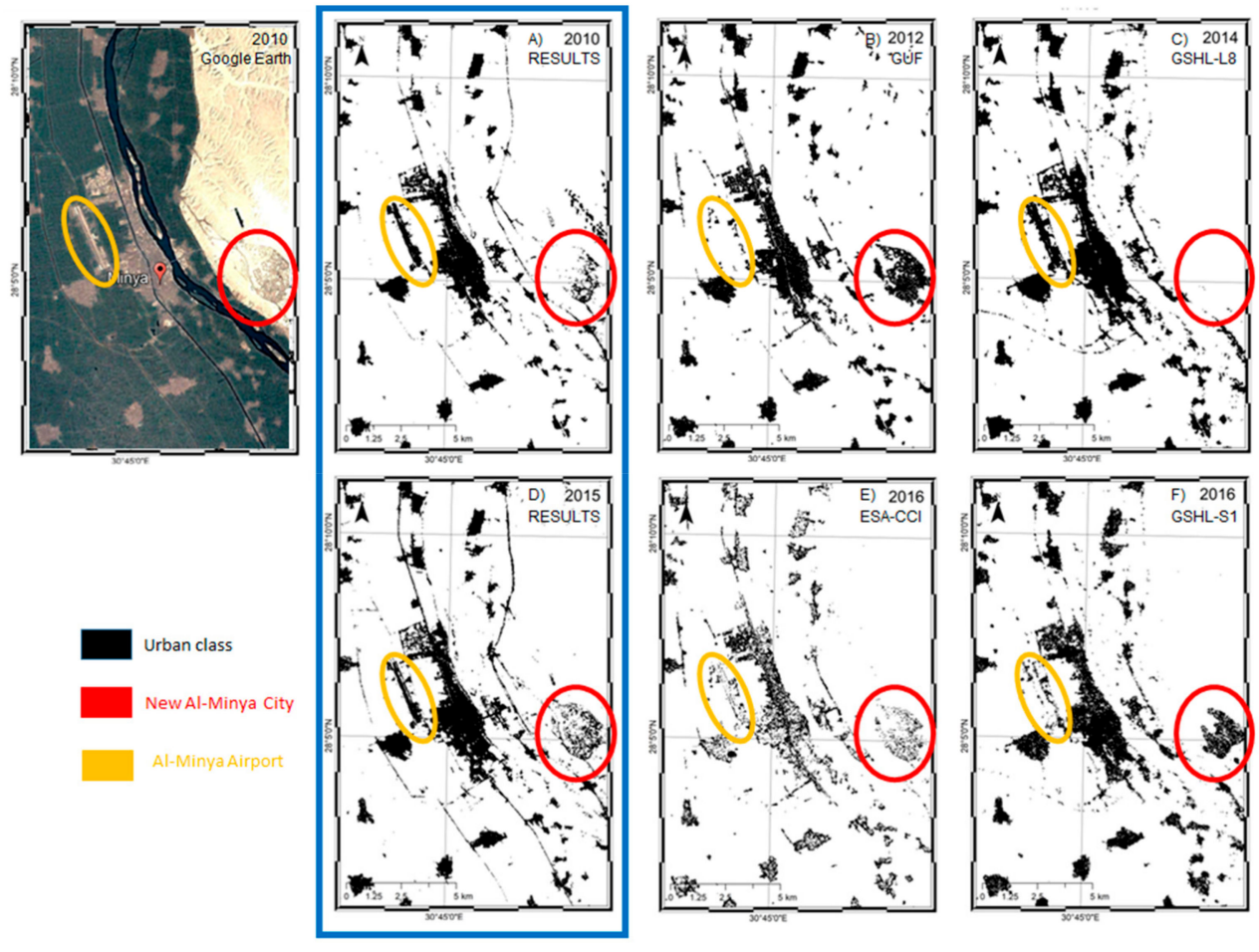

Figure 9. Urban/built-up area of El-Minya city and surroundings from the different datasets: (A) 2010, this study, (B) GUF for 2012, (C) GHSL-L8 2014, (D) 2015, this study, (E) ESA-CCI Prototype 2016 and (F) GHSL-S1 2016. In colour circles, different areas highlighting different classification performances. The blue rectangle highlights our results. 


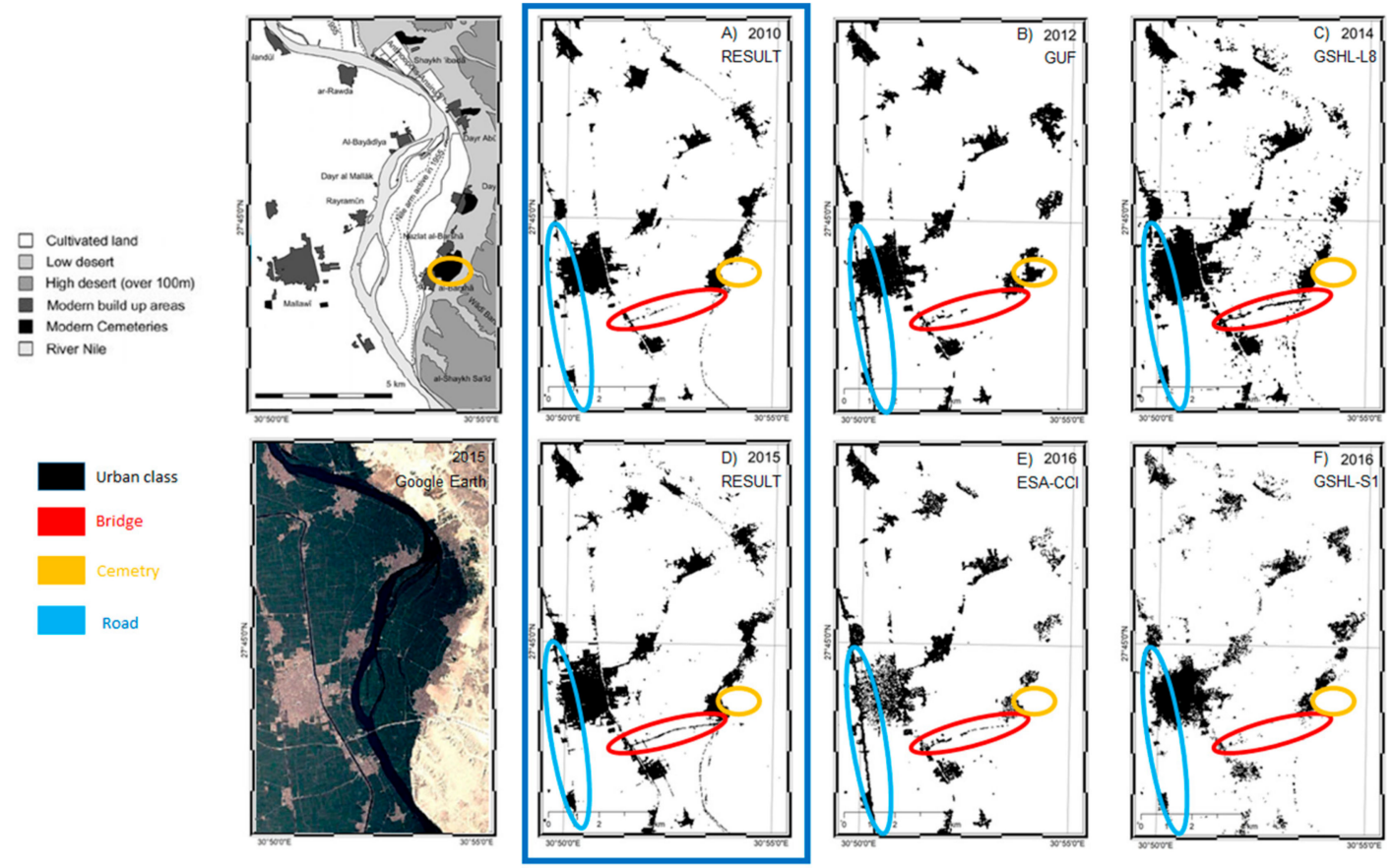

Figure 10. Urban/built-up of Mallawi city and surroundings from the different datasets: (A) 2010, this study, (B) GUF for 2012, (C) GHSL-L8 2014, (D) 2015, this study, (E) ESA-CCI Prototype 2016 and (F) GHSL-S1 2016. Top left map showing the location of modern cemeteries [55]. In colour circles different areas highlighting different classification performances. The blue rectangle highlights our results.

\section{Discussion}

\subsection{Quality of the Data Fusion Approach Compared to Single Platform Approaches}

Table 7 and Figures 9 and 10 compare the results of urban expansion obtained in this study with the data fusion approach to urban global datasets, as well as with a high-resolution visual Google Earth image. A direct and accurate comparison, however, is complicated as the timing of the imagery is different, such that discrepancies between the various urban maps are not solely related to differences in methodology but partly also to real changes in urban extent between the periods covered by each map. Nevertheless, some differences emerge from this comparison. The Global Urban Footprint dataset [47,48] does not detect flat urban areas, such as the Minya airport tracks (see Figure 9-yellow oval), as the method employed is optimised for the detection of man-made building structures with a vertical component. Both Sentinel products (ESA-CCI and GHSL-S1) are also having difficulties in mapping the spatial extent of the airport correctly. Only the data fusion approach (this study) and the GHSL-L8 dataset correctly identifies these flat urbanised areas. On the other hand, narrower strips of urban land, such as road surfaces, are in some cases mapped by the GUF and ESA-CCL dataset but not by the data fusion approach (Figure 10 - blue oval). This could be related to the resolution of the imagery used to create these maps. Indeed, the GUF and ESA-CCL maps are using 12 and $20 \mathrm{~m}$ resolution data, respectively, whilst in this study, we used 30-m resolution data. A 30-m resolution image could be too low to identify narrow roads accurately. The newly constructed Nile bridge and access road (Figure 10-red oval) is identified relatively well on most images, except the GSHL-S1 dataset. Note that road construction started in 2008-2009 and that the bridge and road were only finished in 2013-2014. Hence, the differences in mapping quality between the various datasets likely correspond to the building progress. The GHSL-L8 dataset performs very poorly when it comes to detecting the new urban expansions of New Minya (red oval in Figure 9). The GUF and GSHLS1 data seem to overestimate the urban density of this new settlement and suggest a similar density as the 
ancient city center. However, this is not observed, i.e.,the new town has more open spaces and parts are not yet developed. Here, the data fusion approach correctly predicts the expansion of the new town between 2010 and 2014 but at a lower density than the El-Minya city center itself. Furthermore, the ESA-CCI classifies many city centers as bare soil, thus showing a lower built-up density (Figure 9 El-Minya city and Figure 10 Mallawi city center). We attribute this to the fact that many buildings have similar spectral properties as bare soil: many buildings have been constructed from soil material (mud bricks) and deposition of dust on rooftops and against buildings walls in this extremely dry environment may also contribute to this effect. Finally, some large cemeteries can be found along the Eastern Desert margin (Figure 10-yellow). These cemeteries are mapped as built-up on the GUF map but could be erroneously understood as urban.

Overall, the detailed comparisons of the various urban datasets show that in general, the data fusion approach outperforms the quality of the global urban datasets that are constructed from a single data platform, whether it is optical or radar data. In particular, the data fusion of radar and optical imagery is able to correctly capture the extent of urban areas s.s., i.e., buildings. Errors in the classification of roads are probably related to the lower resolution. Our results also show that comparing data on the urban extent mapped using different approaches is not an accurate method to map and quantify rates of urban expansion through time. Table 7 could incorrectly suggest urban expansion took place between 2010 and 2014 (from 109 to $207 \mathrm{~km}^{2}$ ), followed by a significant reduction in urban expansion in 2015 (again $148 \mathrm{~km}^{2}$ ). In the next section, we will, therefore, discuss changes in urban and agricultural land areas using a single methodology, i.e., the data fusion approach applied to 1998, 2004, 2010 and 2015 imagery.

\subsection{Urban and Agricultural Land Dynamics}

Urbanisation follows a trend that accelerated during the last period analysed (see Table 6). Whereas urbanisation rates were already high in the first two periods, 2.5 and $1.8 \mathrm{~km}^{2} /$ year for the periods 1998-2004 and 2004-2010, respectively, it is mainly in the period 2010-2015 that new urban land was created at a rate of $6.1 \mathrm{~km}^{2} /$ year. Urban expansion is mainly linked to a reduction in arable land ("fields" class) within the floodplain (compare Figures 6 and 7). This type of urban expansion typically involves a diffusion process whereby cities and villages grow along their edges. This is illustrated in the area around the city of Mallawi in the El-Minya governorate (Figure 11). No less than $60 \%$ of the urban growth near Mallawi between 1998 and 2015 took place in the last five years. It involved mainly new building blocks to the north and south of the city of Mallawi. In more recent time periods, however, urbanisation is no longer restricted to the floodplain. Table 5 shows how between 2010 and 2015, a significant part of the urban expansion took place in the desert. This is strongly linked to government-led urban planning whereby new cities are built in desert areas, such as New Minya, located within the eastern desert (see Figure 9, red circle). Around Caïro, desert cities such as 6th of October City, 10th of Ramadan City and New Cairo, amongst others, have been developed since the 1970s and 1980s [56]. This process has also gradually impacted Middle and Upper Egypt from the 1990s and 2000s onwards, with new towns being planned near Minya, Assiut and Qena, amongst others [57].

Urban expansion goes hand in hand with a reduction in land used for agricultural activities in the Nile floodplain: $53 \mathrm{~km}^{2}$ of arable land has been irreversibly converted into urban land between 1998 and 2015 in the entire study area (Table 5). However, this does not imply that agricultural land is decreasing. In the same period, no less than $260 \mathrm{~km}^{2}$ of barren desert or former dunes has been reclaimed for agricultural purposes. This includes areas in the western and eastern desert where large-scale irrigation schemes have been set up, as well as dune-levelling in the interaction area [14]. Figure 7 shows that the levelling of dunes in the interaction area already started in the late 1990s, whereas land reclamation in the desert is a more recent phenomenon. It is mainly the latter process which is responsible for the increasing rate at which new agricultural land is created. These two phenomena are also illustrated in Figures 12 and 13 respectively. 
The aim of the Egyptian government with the new-town policy has been to release pressure on the fertile agricultural land with a rising population and to improve the living conditions in highly populated ancient urban centers [56]. However, whilst our data indeed shows that urban expansion in the desert takes place at increasing rates, it is clear that urban expansion in the Nile Valley is far more important in absolute numbers. Contrary to the planned desert cities, this type of urban expansion is not planned and often informal [58]. Between 1998 and 2015, approximately 1500 ha of fertile land has still been converted into urban land each year. Despite the overall increase in arable land through land reclamation in the desert, it cannot keep pace with increasing population numbers. In the El-Minya governorate, the average extent of agricultural land per inhabitant has decreased from 4.7 to $3.7 \mathrm{ha} /$ person, i.e., a reduction of $21 \%$ over 17 years. Hence, we can conclude that at least for Middle Egypt, the new town policy did not halt the reduction in the availability of fertile soils for crop cultivation. Newly reclaimed areas are also more vulnerable as water has to be pumped from the Nile Valley or from groundwater resources, which is not only very costly but it may also lead to failures in water supply in the case of malfunctioning systems, thus questioning the sustainability of this type of agriculture (e.g., [59,60]). On the other hand, urban population density decreased from 46,000 to 35,400 inhabitants/ $\mathrm{km}^{2}$ built-up area in the same period (Figure 8 ). Despite this reduction, these average urban population densities of more than 350 people per hectare remain very high to global standards [61]. Furthermore, population densities in the new desert towns are often lower as more open spaces are provided and not all towns are yet successful. For New Minya, the population is currently estimated at 45,000, whilst it should reach 638,000 in 2050 [62].This means that population densities in the towns and villages in the Nile Valley so far remain densely populated, similar to many residential areas in Greater Cairo [63]. Furthermore, contrary to the planned desert cities, this type of urban expansion is not planned and often informal [58]. Hence, living conditions remain in general very poor.

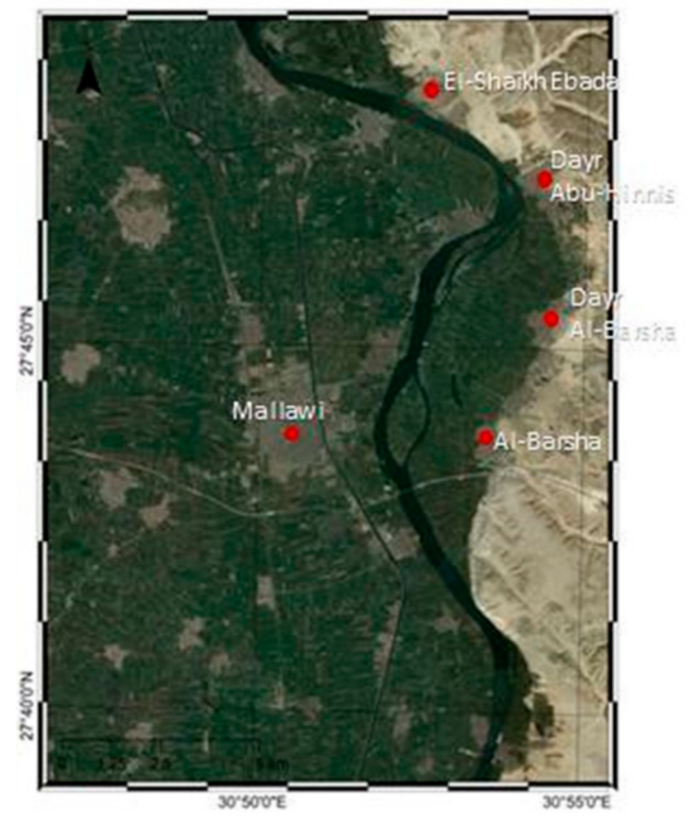

Background image with source: Esri, DigitalGlobe, GeoEye, Earthstar Geographics, CNES/Airbus DS, USDA, USGS, AeroGRID, IGN, and the GIS User Community

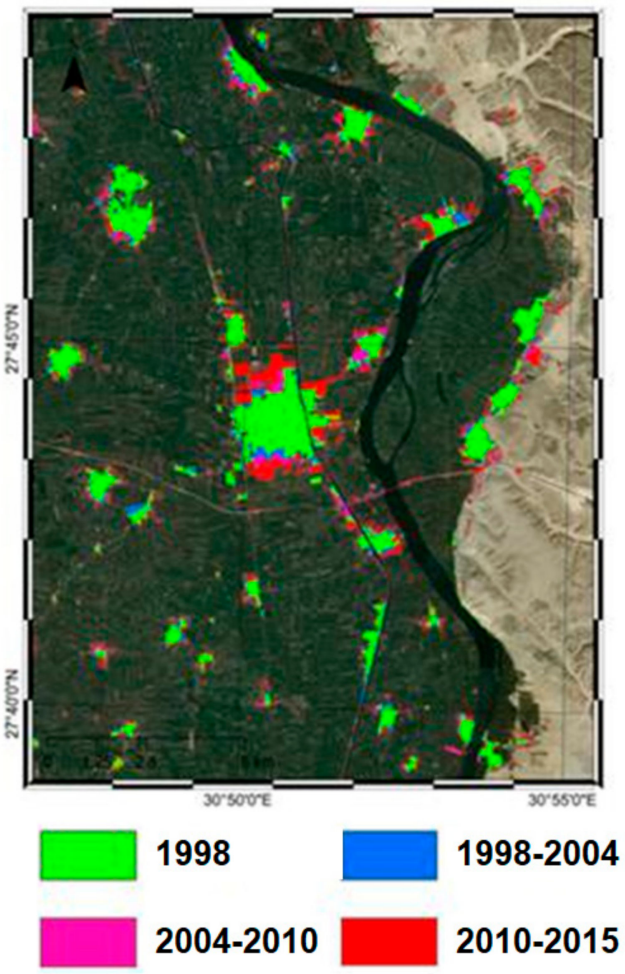

Figure 11. Urban classes detected for 1998, 2004, 2010 and 2015 in Mallawi province overlaid on optical image (right) and optical image over the area (left). 


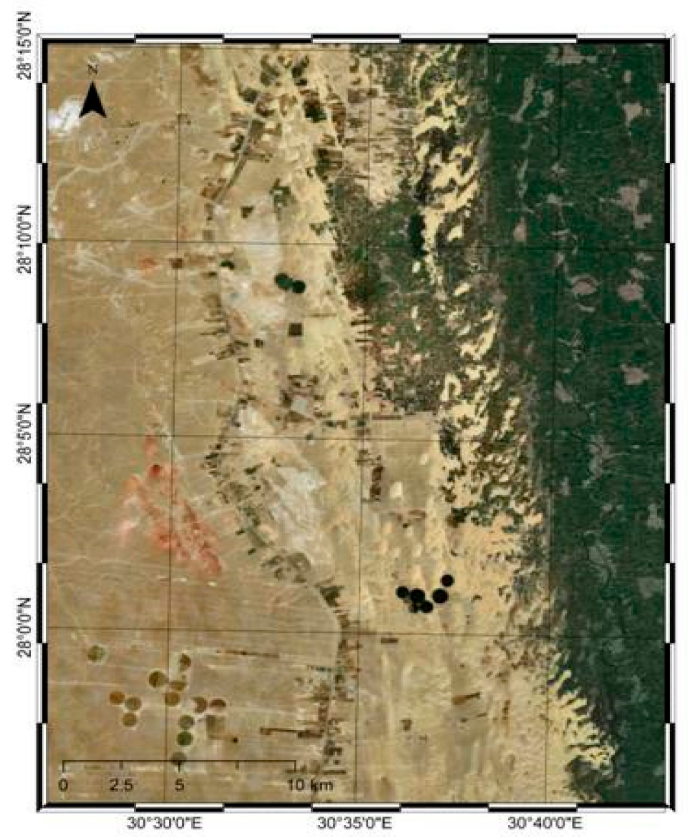

Background image with source: Esri, DigitalGlobe, GeoEye, Earthstar Geographics CNES/Airbus DS, USDA USGS, AeroGRID, IGN and the GIS User Community

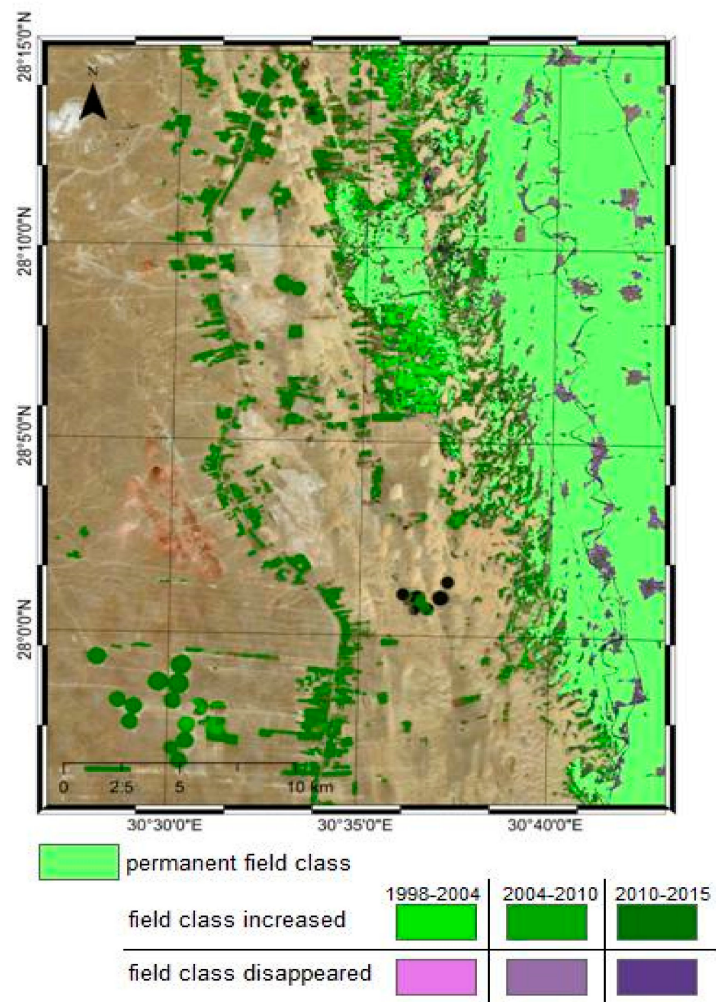

Figure 12. Field classes detected for 1998, 2004, 2010 and 2015 in the Eastern South-Rayan dune field area overlaid on high-resolution optical image (right) and optical image over the area (left).

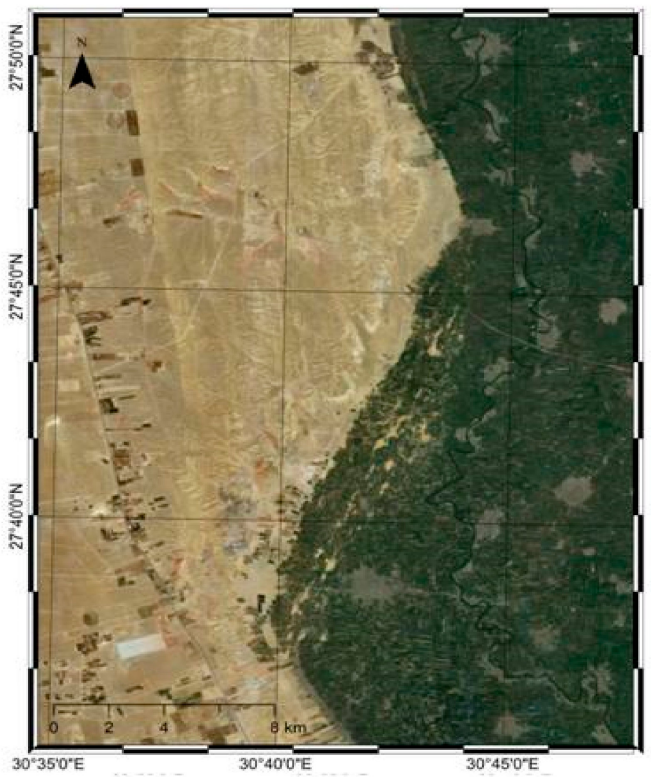

Background image with source: Esri,

DigitalGlobe, GeoEye, Earthstar Geographics,

CNES/Airbus DS, USDA, USGS, AeroGRID, IGN

and the GIS User Community

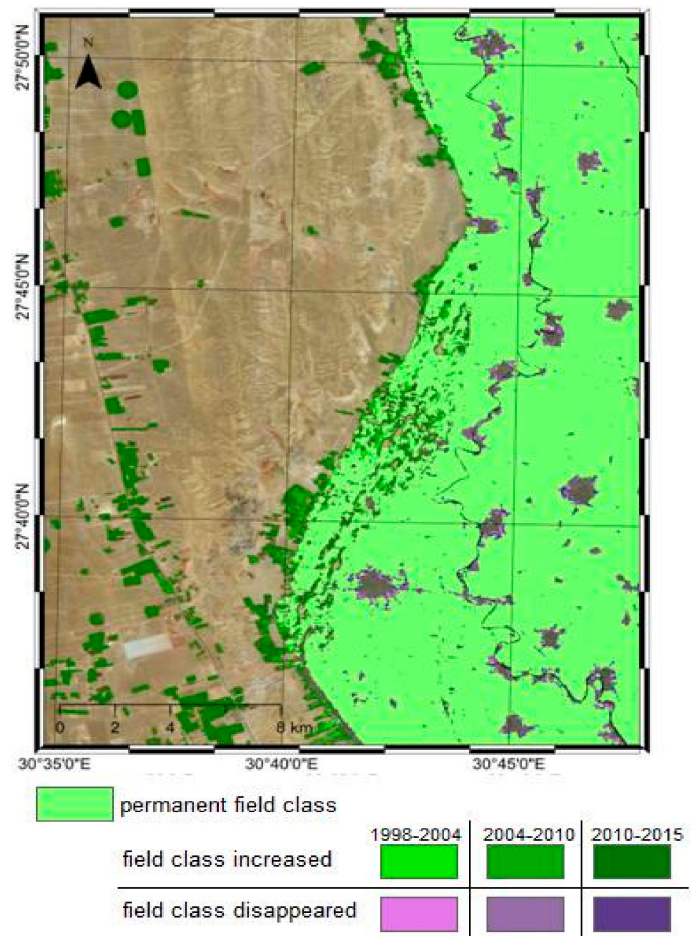

Figure 13. Field classes detected for 1998, 2004, 2010 and 2015 in the Western Dalija region overlaid on a high-resolution optical image (right) and optical image over the area (left). 


\section{Conclusions}

In this study, we applied a data-fusion approach to map land-use dynamics in Middle Egypt for the period 1998-2015. Our data-fusion approach proved to be an effective method to discriminate urban areas where other approaches fail, especially when urban areas are built with mud bricks or constructed within desert areas. The combination of optical imagery (Landsat 5 TM, 7 ETM+ and 8 OLITIRS) with radar imagery (ERS-2 SAR, Envisat ASAR and Sentinel-1 IW) resulted in four multi-temporal land cover maps at a resolution of $30 \mathrm{~m}$. Comparison with high-resolution optical images (Google Earth) showed very high accuracy, stressing the efficacy of the data-fusion approach in mapping land cover dynamics. Furthermore, comparison with globally available urban datasets shows that the data fusion approach is performing better than the single platform-based approaches when it comes to identifying new settlements in the desert or to discriminate urban buildings from bare arable land. Our study also suggests that multi-temporal studies on the land cover that combine results from various producers obtained with different methodologies could lead to erroneous nonrealistic interpretations.

Our data show a rapidly increasing trend in urbanisation in Middle Egypt $\left(65 \mathrm{~km}^{2}\right)$, in particular, along the margins of existing towns and villages in the Nile Valley. As a result, a continuous decrease of fertile Nile floodplain soils for agricultural practices can be seen. This loss is compensated by land reclamation processes whereby former dunes in the Nile Valley are levelled, and by irrigation practices in the desert (over $200 \mathrm{~km}^{2}$ ). Additionally, the results show that both the urban population density and the amount of agricultural land per person have decreased by more than $20 \%$ since 1998 . Finally, we have demonstrated that the proposed data-fusion approach is a viable tool to continuously monitor future land cover changes and can be used to update the management and planning of urban areas.

Author Contributions: Conceptualisation, G.V.; J.M.D.B.; and R.F.H.; Formal analysis, J.M.D.B., G.V. and R.F.H.; Funding acquisition, G.V. and R.F.H.; Investigation, J.M.D.B., G.V. and R.F.H., Methodology, J.M.D.B. and F.C.; Project administration, G.V.; Resources, R.F.H. and G.V.; Software, J.M.D.B. and F.C.; Supervision, R.F.H. and G.V.; Validation, J.M.D.B.; Visualisation, J.M.D.B.; Writing-original draft, by all the authors; Writing-review and editing, by all authors. All authors have read and agreed to the published version of the manuscript.

Funding: This research is within the framework of the APLADYN project funded by the STEREO II-program of the Belgian Science Policy—project SR/00/132.

Acknowledgments: The authors acknowledge the usage of Landsat TM, ETM+ and OLITIRS images available from http://earthexplorer.usgs.gov through Google Earth Engine and the ERS SAR and Envisat ASAR imagery provided by ESA under the CAT-1 C1P.8230. This study contains modified Copernicus Sentinel data [2015]. The authors acknowledge as well as the German Space Agency, the Joint Research Center and the ESA CCI initiative for providing us with their global layers employed to verify the goodness of our results. We want also to thank the ESA Research and Service Support for the provision of computing resources employed in this work. Extracted layers over Egypt downloaded from [64]. The suggestions and recommendations by the anonymous reviewers that contributed to improving the manuscript are also acknowledged.

Conflicts of Interest: The authors declare no conflict of interest.

\section{References}

1. Vermeiren, K.; Van Rompaey, A.; Loopmans, M.; Serwajja, E.; Mukwaya, P. Urban growth of Kampala, Uganda: Pattern analysis and scenario development. Landsc. Urban Plan. 2012, 106, 199-206. [CrossRef]

2. Cohen, B. Urbanization in developing countries: Current trends, future projections, and key challenges for sustainability. Technol. Soc. 2006, 28, 63-80. [CrossRef]

3. Cobbinah, P.B.; Erdiaw-Kwasie, M.O.; Amoateng, P. Africa's urbanisation: Implications for sustainable development. Cities 2015, 47, 62-72. [CrossRef]

4. Sutton, K.; Fahmi, W. Cairo's urban growth and strategic master plans in the light of Egypt's 1996 population census results. Science 2001, 18, 135-149. [CrossRef]

5. Harris, R.; Wahba, M. The Urban Geography of Low-Income Housing: Cairo (1947-96) Exemplifies a Model. Int. J. Urban Reg. Res. 2002, 26, 58-79. [CrossRef]

6. Schneider, A.; Woodcock, C.E. Compact, dispersed, fragmented, extensive? A comparison of urban growth in twenty-five global cities using remotely sensed data, pattern metrics and census information. Urban Stud. 2008, 45, 659-692. [CrossRef] 
7. Ward, D.; Phinn, S.R.; Murray, A.T. Monitoring growth in rapidly urbanizing areas using remotely sensed data. Prof. Geogr. 2000, 52, 371-386. [CrossRef]

8. Griffiths, P.; Hostert, P.; Gruebner, O.; van der Linden, S. Mapping megacity growth with multi-sensor data. Remote Sens. Environ. 2010, 114, 426-439. [CrossRef]

9. Hou, H.; Estoque, R.C.; Murayama, Y. Spatiotemporal analysis of urban growth in three African capital cities: A grid-cell-based analysis using remote sensing data. J. Afr. Earth Sci. 2016, 123, 381-391. [CrossRef]

10. Brinkmann, K.; Schumacher, J.; Dittrich, A.; Kadaore, I.; Buerkert, A. Analysis of landscape transformation processes in and around four West African cities over the last 50 years. Landsc. Urban Plan. 2012, 105, 94-105. [CrossRef]

11. Li, Y. Urban-rural interaction patterns and dynamic land use: Implications for urban-rural integration in China. Reg. Environ. Chang. 2012, 12, 803-812. [CrossRef]

12. Inostroza, L.; Hamstead, Z.; Spyra, M.; Qhreshi, S. Beyond urban-rural dichotomies: Measuring urbanisation degrees in central European landscapes using the technomass as an explicit indicator. Ecol. Indic. 2019, 96, 466-476. [CrossRef]

13. Embabi, N.S. The geomorphology of Egypt, landforms and evolution, Volume I: The Nile Valley and the Western Desert. Spec. Pub. Egypt. Geogr. Soc 2004, 447.

14. Mohamed, I.N.L.; Verstraeten, G. Analyzing dune dynamics at the dune-field scale based on multi-temporal analysis of Landsat-TM images. Remote Sens. Environ. 2012, 119, 105-117. [CrossRef]

15. Willems, H.; Dahms, J.-M. (Eds.) The Nile: Natural and Cultural Landscape in Egypt. In Proceedings of the International Symposium, L'Ecole du Val-de-Grâce, Paris, France, 22-23 February 2013; Transcript Verlag: Bielefeld, Germany, 2013; p. 14957BC, ISBN 9783837636154.

16. De Noronha Vaz, E.; Caetano, M.; Nijkamp, P. A multi-level spatial urban pressure analysis of the Giza pyramid plateau in Egypt. J. Herit. Tour. 2011, 6, 99-108. [CrossRef]

17. Hassan, A.A.M. Change in the urban spatial structure of the Greater Cairo metropolitan area, Egypt. Archives 2011, XXXVIII, 133-136.

18. Delgado Blasco, J.M.; Verstraeten, G.; Hanssen, R.F. Detecting modern desert to urban transitions from space in the surroundings of the Giza World Heritage site and Greater Cairo. J. Cult. Herit. 2016, 23, 71-78. [CrossRef]

19. Mohamed, H.E. Analysis of urban growth at Cairo, Egypt using remote sensing and GIS. Nat. Sci. 2012, 4, 355-361.

20. Taubenböck, H.; Wegmann, M.; Roth, A.; Mehl, H.; Dech, S. Analysis of urban sprawl at mega city Cairo, Egypt using multisensoral remote sensing data, landscape metrics and gradient analysis. Area 2008.

21. Osman, T.; Arima, T.; Divigalpitiya, P. Measuring urban sprawl patterns in Greater Cairo Metropolitan Region. J. Indian Soc. Remote Sens. 2016, 44, 287-295. [CrossRef]

22. Stewart, D.J.; Yin, Z.; Bullard, S.M.; Maclachlan, J.T. Assessing the spatial structure of urban and population growth in the greater Cairo area, Egypt: A GIS and imagery analysis approach. Urban Stud. 2004, 41, 95-117. [CrossRef]

23. El-Bayomi, G.; Ali, R.R. Assessment of Urban Sprawl on El Minya Archeological Sites, Egypt. J. Appl. Sci. 2015, 15, 264-270.

24. Wikipedia Mallawi. Available online: https:/en.wikipedia.org/wiki/Mallawi (accessed on 29 June 2018).

25. Kalensky, Z.D. AFRICOVER land cover database and map of Africa. Can. J. Remote Sens. 1998, 24, $292-297$. [CrossRef]

26. Lesiv, M.; Fritz, S.; McCallum, I.; Tsendbazar, N.; Herold, M.; Pekel, J.-F.; Buchhorn, M.; Smets, B.; Van De Kerchove, R. Evaluation of ESA CCI Prototype Land Cover Map at 20m; IIASA: Laxenburg, Austria, 2017.

27. Tupin, F. Fusion of optical and SAR images. In Radar Remote Sens. Urban Areas; Springer: Berlin/Heidelberg, Germany, 2010; pp. 133-159.

28. Joshi, N.; Baumann, M.; Ehammer, A.; Fensholt, R.; Grogan, K.; Hostert, P.; Jepsen, M.; Kuemmerle, T.; Meyfroidt, P.; Mitchard, E.; et al. A review of the application of optical and radar remote sensing data fusion to land use mapping and monitoring. Remote Sens. 2016, 8, 70. [CrossRef]

29. El Gammal, E.S.A.; El Gammal, A.E.D.A. Hazard impact and genetic development of sand dunes west of Samalut, Egypt. Egypt. J. Remote Sens. Sp. Sci. 2010, 13, 137-151. [CrossRef] 
30. Gorelick, N. Google Earth Engine. In Proceedings of the AGU Fall Meeting Abstracts; American Geophysical Union: San Francisco, CA, USA, 2012; Volume 1, p. 4.

31. Delgado Blasco, J.M.; Sabatino, G.; Cuccu, R.; Rivolta, G.; Marchetti, P.G. Research and Service Support: Bringing Users to Data. In Proceedings of the Living Planet Symposium; ESA, Ed.; European Space Agency: Prague, Czech Republic, 2016; Volume 740, p. 271.

32. ARRAY. NEST-Calibration Operator. Available online: http://corp.array.ca/nest-web/help/operators/ CalibrationOp.html (accessed on 21 January 2015).

33. Angiuli, E.; Trianni, G. Urban mapping in Landsat images based on normalized difference spectral vector. IEEE Geosci. Remote Sens. Lett. 2014, 11, 661-665. [CrossRef]

34. Aswatha, S.M.; Mukhopadhyay, J.; Biswas, P.K. Spectral slopes for automated classification of land cover in landsat images. In Proceedings of the 2016 IEEE International Conference on Image Processing (ICIP), Phoenix, AZ, USA, 25-28 September 2016; pp. 4354-4358.

35. Li, S.; Chen, X. A new bare-soil index for rapid mapping developing areas using landsat 8 data. Int. Arch. Photogramm. Remote Sens. Spat. Inf. Sci. 2014, 40, 139. [CrossRef]

36. Silleos, N.G.; Alexandridis, T.K.; Gitas, I.Z.; Perakis, K. Vegetation indices: Advances made in biomass estimation and vegetation monitoring in the last 30 years. Geocarto Int. 2006, 21, 21-28. [CrossRef]

37. Zhou, Y.; Yang, G.; Wang, S.; Wang, L.; Wang, F.; Liu, X. A new index for mapping built-up and bare land areas from Landsat-8 OLI data. Remote Sens. Lett. 2014, 5, 862-871. [CrossRef]

38. López-Caloca, A.A. Data fusion approach for Urban area identification using multisensor information. In Proceedings of the 8th International Workshop on the Analysis of Multitemporal Remote Sensing Images (Multi-Temp), Annecy, France, 22-24 July 2015.

39. Patel, N.N.; Angiuli, E.; Gamba, P.; Gaughan, A.; Lisini, G.; Stevens, F.R.; Tatem, A.J.; Trianni, G. Multitemporal settlement and population mapping from Landsat using Google Earth Engine. Int. J. Appl. Earth Obs. Geoinf. 2015, 35, 199-208. [CrossRef]

40. Trianni, G.; Angiuli, E.; Lisini, G.; Gamba, P. Human settlements from landsat data using google earth engine. In Proceedings of the 2014 IEEE Geoscience and Remote Sensing Symposium, Quebec City, QC, Canada, 13-18 July 2014; IEEE: Piscataway, NJ, USA, 2014; pp. 1473-1476.

41. McInerney, D.; Kempeneers, P. Pktools. In Open Source Geospatial Tools; Springer: Berlin/Heidelberg, Germany, 2015; pp. 173-197.

42. Vapnik, V.N. Statistical Learning Theory; John Wiley \& Sons: New York, New York, USA, 1998.

43. Keerthi, S.S.L.C.J. Asymptotic behaviors of support vector machines with Gaussian kernel. Neural Comput. 2003, 15, 1667-1689. [CrossRef] [PubMed]

44. Cohen, J. A Coefficient of Agreement for Nominal Scales. Educ. Psychol. Meas. 1960, 20, 37-46. [CrossRef]

45. Congalton, R.G. A Review of Assessing the Accuracy of Classifications of Remotely Sensed Data. Remote Sens. Environ. 1991, 46, 35-46. [CrossRef]

46. Mather, P.M.; Koch, M. Computer Processing of Remotely-Sensed Images: An introduction, 3rd ed.; John Wiley \& Sons Ltd.: Chichester, UK, 2004; ISBN 0470849193.

47. Esch, T.; Heldens, W.; Hirner, A.; Keil, M.; Marconcini, M.; Roth, A.; Zeidler, J.; Dech, S.; Strano, E. Breaking new ground in mapping human settlements from space-The Global Urban Footprint. ISPRS J. Photogramm. Remote Sens. 2017, 134, 30-42. [CrossRef]

48. Esch, T.; Schenk, A.; Ullmann, T.; Thiel, M.; Roth, A.; Dech, S. Characterization of land cover types in TerraSAR-X images by combined analysis of speckle statistics and intensity information. IEEE Trans. Geosci. Remote Sens. 2011, 49, 1911-1925. [CrossRef]

49. European Space Agency CCI Land Cover -Sentinel-2 Prototype Land Cover 20m of Africa 2016. Available online: http://2016africalandcover20m.esrin.esa.int/ (accessed on 9 September 2018).

50. Florczyk, A.; Politis, P.; Corbane, C.; Pesaresi, M. GHS-BUILT R2018A—GHS built-up grid INPUT DATA, Landsat multitemporal collections (1975-1990-2000-2014). European Commission, Joint Research Centre (JRC). Available online: http://data.europa.eu/89h/jrc-ghsl-10009 (accessed on 10 September 2018).

51. Corbane, C.; Politis, P.; Syrris, V.; Pesaresi, M. GHS built-up grid, derived from Sentinel-1 (2016), R2018A. European Commission, Joint Research Centre (JRC). Available online: http://data.europa.eu/89h/jrc-ghsl10008 (accessed on 10 September 2018). 
52. Corbane, C.; Pesaresi, M.; Politis, P.; Syrris, V.; Florczyk, A.J.; Soille, P.; Maffenini, L.; Burger, A.; Vasilev, V.; Rodriguez, D.; et al. Big earth data analytics on Sentinel-1 and Landsat imagery in support to global human settlements mapping. Big Earth Data 2017, 1, 118-144. [CrossRef]

53. Central Agency for Public Mobilization and Statistics (CAPMAS). Census Data. Available online: https: //egypt.opendataforafrica.org/data\#source=CAPMAS (accessed on 10 June 2019).

54. Landis, J.R.; Koch, G.G. The measurement of observer agreement for categorical data. Biometrics 1977, 159-174. [CrossRef]

55. Willems, H.M.W.M. A note on the origin of the toponym al-Barshā. J. Egypt. Archaeol. 2010, 96, $232-236$. [CrossRef]

56. Stewart, D.J. Cities in the desert: The Egyptian new-town program. Ann. Assoc. Am. Geogr. 1996, 86, 459-480. [CrossRef]

57. Ibrahim, M.R.; Masoumi, H.E. Will Distance to the Capital City Matter When Supplying New Cities in Egypt? GeoScape 2016, 10, 35-52. [CrossRef]

58. Hegazy, I.R. Informal settlement upgrading policies in Egypt: Towards improvement in the upgrading process. J. Urban. Int. Res. Placemaking Urban Sustain. 2016, 9, 254-275. [CrossRef]

59. Adriansen, H.K. Land reclamation in Egypt: A study of life in the new lands. Geoforum 2009, 40, 664-674. [CrossRef]

60. Barnes, J. Pumping possibility: Agricultural expansion through desert reclamation in Egypt. Soc. Stud. Sci. 2012, 42, 517-538. [CrossRef]

61. Angel, S.; Parent, J.; Civco, D.L.; Blei, A.M. Persistent Decline in Urban Densities: Global and Historical Evidence of 'Sprawl'; Lincoln Institute of Land Policy: Cambridge, MA, USA, 2010.

62. New Urban Communities Authorities. New Minia. Available online: http://www.newcities.gov.eg/english/ New_Communities/Minia/default.aspx (accessed on 23 December 2019).

63. Harms, H. Challenges for sustainable development of informal settlements and of desert new towns in Cairo. In Revitalizing City Districts; Springer: Berlin/Heidelberg, Germany, 2017; pp. 147-169.

64. Database of Global Administrative Areas (GADM). Egypt Administrative Boundaries. Available online: https://gadm.org/ (accessed on 7 July 2017).

(C) 2020 by the authors. Licensee MDPI, Basel, Switzerland. This article is an open access article distributed under the terms and conditions of the Creative Commons Attribution (CC BY) license (http://creativecommons.org/licenses/by/4.0/). 